\title{
Machine learning-based retrieval of benthic reflectance and Posidonia oceanica seagrass extent using a semi-analytical inversion of Sentinel-2 satellite data
}

\section{Dimosthenis Traganos \& Peter Reinartz}

To cite this article: Dimosthenis Traganos \& Peter Reinartz (2018): Machine learningbased retrieval of benthic reflectance and Posidonia oceanica seagrass extent using a semianalytical inversion of Sentinel-2 satellite data, International Journal of Remote Sensing, DOI: 10.1080/01431161.2018.1519289

To link to this article: https://doi.org/10.1080/01431161.2018.1519289

$$
\text { Published online: } 11 \text { Oct } 2018 .
$$

Submit your article to this journal $\sqsubset$ 


\title{
Machine learning-based retrieval of benthic reflectance and Posidonia oceanica seagrass extent using a semi-analytical inversion of Sentinel-2 satellite data
}

\author{
Dimosthenis Traganos (10) and Peter Reinartz ${ }^{\mathrm{b}}$
}

a Department of Photogrammetry and Image Analysis, Remote Sensing Technology Institute, German

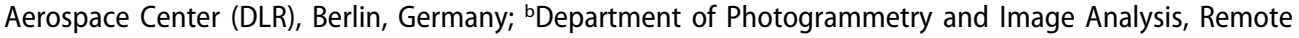
Sensing Technology Institute, German Aerospace Center (DLR), Oberpfaffenhofen, Germany

\begin{abstract}
In the epoch of the human-induced climate change, seagrasses can mitigate the resulting negative impacts due to their carbon sequestration ability. The endemic and dominant in the Mediterranean Posidonia oceanica seagrass contains the largest stocks of organic carbon among all seagrass species, yet it undergoes a significant regression in its extent. Therefore, suitable quantitative assessment of its extent and optically shallow environment are required to allow good conservation and management practices. Here, we parameterise a semi-analytical inversion model which employs above-surface remote sensing reflectance of Sentinel-2A to derive water column and bottom properties in the Thermaikos Gulf, NW Aegean Sea, Greece (eastern Mediterranean). In the model, the diffuse attenuation coefficients are expressed as functions of absorption and backscattering coefficients. We apply a comprehensive pre-processing workflow which includes atmospheric correction using C2RCC (Case 2 Regional CoastColour) neural network, resampling of the lower spatial resolution Sentinel-2A bands to $10 \mathrm{~m} /$ pixel, as well as empirical derivation of water bathymetry and machine learning-based classification of the resulting bottom properties using the Support Vector Machines. SVM-based classification of benthic reflectance reveals $\sim 300$ ha of $P$. oceanica seagrass between 2 and 16 $\mathrm{m}$ of depth, and yields very high producer and user accuracies of $95.3 \%$ and $99.5 \%$, respectively. Sources of errors and uncertainties are discussed. All in all, recent advances in Earth Observation in terms of optical satellite technology, cloud computing and machine learning algorithms have created the perfect storm which could aid high spatiotemporal, large-scale seagrass habitat mapping and monitoring, allowing for its integration to the Analysis Ready Data era and ultimately enabling more efficient management and conservation in the epoch of climate change.
\end{abstract}

\section{ARTICLE HISTORY}

Received 22 December 2017

Accepted 29 August 2018

\section{Introduction}

In the epoch of climate change that humanity is traversing, the latter has a silent and overlooked, yet remarkably efficient, natural ally in mitigating the impacts of the former:

CONTACT Dimosthenis Traganos dimosthenis.traganos@dlr.de E Remote Sensing Technology Institute, German Aerospace Center (DLR), Rutherfordstraße 2, Berlin 12489,Germany 
seagrasses. Lying in depths between $0-50 \mathrm{~m}$ in all coastal ecosystems worldwide but Antarctica, seagrasses are marine flowering plants which have been relentlessly absorbing and storing carbon dioxide, the so-called 'blue carbon', for millennia (Mateo et al. 1997; Fourqurean et al. 2012). The largest stocks of organic carbon ( $\left.C_{\text {org }}\right)$ among all seagrasses have been documented in the extensive rhizomes of a single seagrass species endemic in the Mediterranean Sea: the iconic Posidonia oceanica (Fourqurean et al. 2012). In addition to blue carbon sequestration, the remarkable efficiency of $P$. oceanica seagrass is attested by an additional plethora of important ecosystem services, namely coastal erosion buffering (Pergent et al. 2012), nursery (Giannoulaki et al. 2013) and fishing grounds (Nordlund et al. 2017), and bio-indicator (Nordlund et al. 2016).

Regardless of their great ecological value which has rendered them as a conservation priority of the European Union and of national legislation, $P$. oceanica beds are facing a threefold problem. First, they have lost up to $38 \%$ of their extent during the last 50 years (Marbà, Díaz-Almela, and Duarte 2014; Telesca et al. 2015; Tomas, Turon, and Romero 2005). Anthropogenic activities including climate change, coastal artificialisation, dredging, trawling, anchoring, and eutrophication (Bonacorsi et al. 2013; Jordà, Marbà, and Duarte 2012; Leriche et al. 2006; Waycott et al. 2009) have mainly caused the observed regression. Second, $P$. oceanica has a slow growth rate of $1-4 \mathrm{~cm} \mathrm{yr}^{-1}$ which makes any regression irreversible. Third and last, there is a notable sparsity or absence of data on the extent of $P$. oceanica seagrass meadows in the southern and eastern Mediterranean (Telesca et al. 2015) which impedes any effort to manage and conserve disturbed areas. Generally, efficient management and conservation of seagrass meadows is explicitly defined as the Sustainable Development Goal 14 (SDG 14) 'Conserve and sustainably use the oceans, seas and marine resources for sustainable development' in the United Nations 2030 Agenda for Sustainable Development (UN 2017).

In an opposed and somewhat parallel trend to the declining extent of $P$. oceanica seagrass, Earth Observation has grown at an unprecedented pace in terms of remote sensing technology (i.e. optical satellite sensors), cloud computing, and related developed models and machine learning algorithms. This combination of recent advances has created the perfect storm which could aid the high spatio-temporal mapping and monitoring of $P$. oceanica seagrass-from a small meadow to the whole extent of the Mediterranean-allowing, in turn, more efficient management and conservation practices.

Remote sensing technology can sense $P$. oceanica meadows which occupy the optically shallow seabed where part of the surface reflectance contains a bottom signal. Optically shallow areas comprise one of the most challenging environments for remote sensing due to the numerous interferences of parameters with the sunlight before this is detected and measured by a spaceborne sensor. To invert bottom and water column properties, and then to obtain quantitative information on optically shallow beds, one has to correct the interferences of the atmosphere, air-water interface and water column. A number of researchers have developed a range of empirical, semi-, and analytical solutions to retrieve properties of interest and ultimately untangle the initially weak bottom signal (Brando et al. 2009; Hedley, Roelfsema, and Phinn 2009; Klonowski, Fearns, and Lynch 2007; Lee et al. 1998, 1999; Lyzenga 1978, 1981; Mobley et al. 2005). Numerous studies have utilised satellite imagery to map the extent of optically shallow P. oceanica seagrass beds (Barillè et al. 2010; Borfecchia et al. 2013; Fornes et al. 2006; 
Matta et al. 2014; Pasqualini et al. 2005; Traganos and Reinartz 2017; Traganos, Cerra, and Reinartz 2017).

In this study, we evaluate the suitability of the first four bands (coastal aerosol, blue, green, red) of the Copernicus Sentinel-2A multispectral satellite for mapping $P$. oceanica seagrass meadows utilising and adapting the semi-analytical inversion model of Lee et al. $(1998,1999)$ in the optically shallow context of the Thermaikos Gulf, NW Aegean Sea, Greece (eastern Mediterranean Sea). Using Random Forest on a multispectral RapidEye time series, Traganos and Reinartz (2018) have revealed that the extent of $P$. oceanica seagrass was decreased by $4.1 \%$ at a pace of $-11.2 \mathrm{ha} / \mathrm{yr}$ between 2011 and 2016. We employed the machine learning algorithm of Support Vector Machines (Vapnik 1995), which has been rarely applied in the shallow water remote sensing domain, to retrieve the benthic reflectance and extent of $P$. oceanica beds in the waters of our survey site which feature great transparency and small depth slope. Furthermore, we utilised the C2RCC (Case 2 Regional CoastColour) neural network (Brockmann et al. 2016) to derive water leaving reflectances as well as specific optical water column properties in addition to estimating satellite-derived bathymetry. As regards to aquatic applications, Sentinel- 2 has been recently used to retrieve water constituents and depth in an oligotrophic lake (Dörnhöfer et al. 2016), to measure retrieve suspended particulate matter and chlorophyll $\mathrm{a}$ in an oyster farming site (Gernez, Doxaran and Barillè, 2017), to correct sun glint over inland and sea waters (Harmel et al. 2018), to qualitatively and quantitatively analyse remote sensing reflectance products $\left(R_{\mathrm{rs}}\right)$, essential in the derivations of near-surface water constituents (Pahlevan et al. 2017), to map the subtidal seagrass extent in two coastal ecosystems (Mediterranean seagrasses) (Topouzelis et al. 2016; Traganos and Reinartz 2017), and to estimate satellite-derived bathymetry and country-scale seagrass distribution in the cloud using the geospatial platform of Google Earth Engine (Traganos et al. 2018a, 2018b). Last but not least, we also aim to put the first stone towards the development of a semi- or automated, cloud-based mapping and monitoring workflow which will integrate seagrass habitats to the concept of Analysis Ready Data (ARD) where each and every physical change of related biophysical parameters (i.e. above-ground biomass, carbon sequestration) will be indexed in the epoch of climate change.

\section{Materials and methods}

\subsection{Study site}

The broader study site here contains 12657 submerged hectares within the southeast Thermaikos Gulf, NW Aegean Sea, Greece (Figure 1). The prevailing climatic, oceanographic, hydrographic and sedimentological conditions of this gulf, as well as the various socio-economic activities in its waters have been thoroughly summarised elsewhere (Traganos and Reinartz 2017). The Thermaikos Gulf is thriving in two types of seagrasses in depths between 1.4 and $16.5 \mathrm{~m}$ : the endemic and dominant in the Mediterranean, Posidonia oceanica and the Cymodocea nodosa species (Traganos and Reinartz 2017; Traganos, Cerra, and Reinartz 2017; Traganos and Reinartz 2018). 


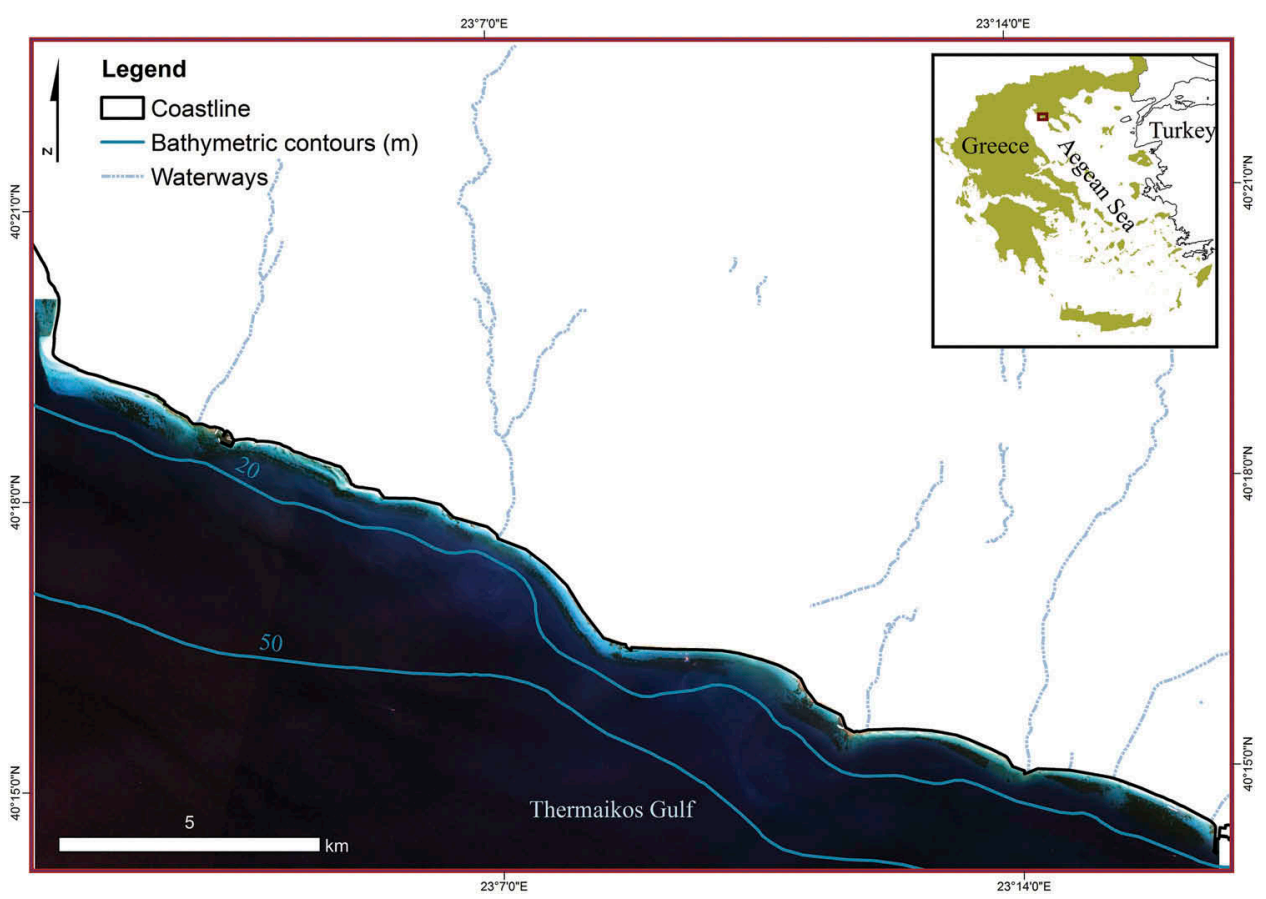

Figure 1. Location of survey site within the Thermaikos Gulf and the Aegean Sea, Greece (inset map). The displayed Sentinel-2A image is a top-of-atmoshpere (toa) 4-3-2 composite in UTM (zone 34) system/WGS84 projection. The depicted bathymetric contours are provided by the Hellenic Navy Hydrographic Service (HNHS). The displayed waterways are provided by the OpenStreetMap (http:// download.geofabrik.de/europe/greece.html).

\subsection{Data}

\subsubsection{Satellite data}

We used Copernicus Sentinel-2A (S2-A) satellite data in the present study. Along with Sentinel-2B, they comprise a system of twin-polar orbiting satellites, Sentinel-2. The first one was launched on 23 June 2015, while the second one on 7 March 2017. European Union's Copernicus programme is the most comprehensive Earth Observation (EO) programme up-to-date. With a free, full and open data policy, this EO programme envisages to tackle global challenges in its six thematic areas: land, marine, atmosphere, climate change, emergency management and security. The Sentinel- 2 constellation carries the MultiSpectral Imager (MSI) instrument which images the Earth's surface from a mean altitude of $786 \mathrm{~km}$, in 13 spectral bands, from the visible-near infrared (VNIR) to the shortwave infrared (SWIR) spectrum at 3 spatial resolutions $(10,20,60 \mathrm{~m})$ with a swath width of $290 \mathrm{~km}$. The combined temporal resolution of the twin satellites is 5 days. Sentinel-2's radiometric resolution of 12bit allows for 4096 brightness levels, which is expected to be beneficial in the delineation of the lower limit of Posidonia oceanica seagrass and optically deep water.

The characteristics of the processed and analysed S2-A image are displayed in Table 1. We downloaded the L1C product of the S2A image from the Sentinel Scientific Data Hub (https://scihub.copernicus.eu/). The selected L1C product consists of $100 \mathrm{~km}^{2}$ orthorectified and spatially co-registered images in Universal Transverse Mercator (UTM)/World Geodetic 
Table 1. Sentinel-2A image characteristics.

\begin{tabular}{lc}
\hline & S2A_MSIL1C_20170330T092021_N0204_R093_- \\
Tile ID & T34TFK_20170330T092849 \\
\hline Acquisition date & 30 March 2017 \\
Acquisition time & 09.20 am UTC \\
Solar zenith angle & $38.75^{\circ}$ \\
Sensor incidence angle & 4.29 \\
Sensor altitude & $786 \mathrm{~km}$ \\
\hline
\end{tabular}

System 1984 (WGS94) projection. The atmospheric correction is conducted with the C2RCC neural network processor through ESA's Sentinel toolbox SNAP. This processor depends on a large database of toa radiances and simulated water leaving reflectances to invert the atmospheric correction spectrum and to retrieve inherent optical properties (IOP) following the training of neural networks. It employs the Hydrolight model for the in-water modelling (Mobley 1994) which derives all relevant IOPs at 443-nm wavelengths (S2 coastal aerosol wavelength). As C2RCC requires all bands in the same resolution, we also used the S2 resampling processor within SNAP, as well, to resample the coarser resolution bands of 60and $20-\mathrm{m}$ to $10-\mathrm{m}$ pixel with a bilinear interpolation. In addition to the upsampling, this approach takes into account the particularities of the Sentinel-2 acquisition angles which can degrade S2-based image analysis by rendering visible the steps between neighbouring granules (Gascon et al. 2017).

\subsubsection{Field and auxiliary data}

The field data collection is described in Traganos and Reinartz (2017). We collected points associated with habitats and corresponding coordinates as well as bathymetric data during a 4-day survey in July 2016. Based on these data and our survey experience, we manually digitised polygons on the L1C image, displaying each of the four habitats present in our survey site (Posidonia oceanica and Cymodocea nodosa seagrasses, sand and photophilous algae-rocks). As we will discuss in section 2.3.3., these polygons were used to train, crossvalidate and test the herein implemented machine learning classifier of Support Vector Machines (SVM). In addition to our own acquisition, we utilised bathymetric data from the Hellenic Navy Hydrographic Service (HNHS) to aid the training and validation of the Satellitederived Bathymetry (SDB) of the Thermaikos Gulf.

\subsection{Methodology}

Here, we utilised the semi-analytical inversion method of Lee et al. $(1998,1999)$ and adapted it to the implemented satellite data and survey site. Based on the quasi-single scattering theory (Gordon, Brown, and Jacobs 1975), the Hyperspectral Optimisation Process Exemplar (HOPE) model has served, in turn, as the basis on which several optically shallow water inversion algorithms have been developed (Brando et al. 2009; Hedley, Roelfsema, and Phinn 2009; Klonowski, Fearns, and Lynch 2007; Mobley et al. 2005). In HOPE, the remote sensing signals of the bottom and water column are mathematically separated and expressed by a few parameters (e.g. bottom reflectance, water depth, and water absorption and backscattering at a single wavelength). The accuracy of these radiative transfer equations (RTE) always depends on the required simplifications which are inherent in their nature. 
Initially, HOPE was developed using Hydrolight (Mobley 1994) to simultaneously derive water depth, bottom reflectance and the various optical water column constituents from $R_{\mathrm{rs}}$ (above-surface remote sensing reflectance) spectra via optimisation. $R_{\mathrm{rs}}$ defined as the ratio of the water leaving radiance to downwelling radiance just above the water surface, is the fundamental parameter upon which all subsequent inversions are based.

In the following paragraphs, we analytically describe how to derive water column and bottom properties from the atmospherically corrected Sentinel-2 visible bands before mapping the Posidonia oceanica seagrass meadows of our survey site. Naturally, in contrast to the 16 bands between 400 and $700 \mathrm{~nm}$ used as an environmental input in the development of HOPE, we adopted a simplified approach, tailored to the multispectral band set of S2; five S2-A bands in the visible range were utilised (coastal aerosol, blue, green, red and vegetation red edge bands at central wavelengths of $443.9\left(\lambda_{1}\right), 496.6\left(\lambda_{2}\right), 560\left(\lambda_{3}\right), 664.5\left(\lambda_{4}\right)$ and $740.2\left(\lambda_{5}\right) \mathrm{nm}$, respectively. The first four bands are the usual suspects in the remote sensing of optically shallow, coastal waters, as they penetrate deeper into the water column, while the vegetation red edge band is used to compensate to a degree for under- or overcorrection of the atmospheric interference. Additionally, we employed the Shortwave Infrared (SWIR) band 11 (central wavelength: $1613.7 \mathrm{~nm}$ ) to mask out all terrestrial features.

\subsubsection{Terrestrial mask}

To further enhance aquatic features, we masked all terrestrial pixels using the resampled SWIR band 11 at $1610 \mathrm{~nm}$. Xu (2006) showed that the use of bands in the SWIR wavelength retrieves information from waterbodies with greater accuracy than the use of Near Infrared (NIR) bands. We applied an Iso Cluster Unsupervised Classification on BOA band 11 to separate terrestrial and aquatic pixels into two classes and subsequently retrieved the latter.

\subsubsection{Semi-analytical inversion of water column properties and benthic reflectance}

2.3.2.1. General description. Remote sensing reflectance above surface, $R_{\mathrm{r} s}$, forms the basis for the inversion of sub-surface properties like the water column constituents, depth and bottom reflectance. In optically shallow waters, numerous parameters contribute to the remotely sensed from a spaceborne sensor $R_{\mathrm{rs}}$, such as the absorption and backscattering coefficients of suspended and dissolved matter, water depth and spectral bottom albedo. For vertically and horizontally homogeneous waters and assuming zero contribution from the water column inelastic scattering to the water leaving radiance, $R_{\mathrm{rs}}$ is conceptually summarised here as:

$$
R_{\mathrm{rs}}(\lambda)=f\left[a(\lambda), b_{\mathrm{b}}(\lambda), \rho(\lambda), H, \theta_{\mathrm{w}}, \theta_{\mathrm{v}}, \varphi\right]
$$

where $a(\lambda)$ is the absorption coefficient, $b_{\mathrm{b}}(\lambda)$ is the backscattering coefficient, $\rho(\lambda)$ is the bottom albedo, $\mathrm{H}$ is the water depth, $\theta_{\mathrm{w}}$ is the sub-surface solar zenith angle, $\theta_{v}$ subsurface sensor viewing angle from nadir, and $\varphi$ is the viewing azimuth angle from the solar plane. For brevity, we will omit the wavelength notation for each wavelengthdependent parameter unless when it is required for clarity.

The resulting reflectance Sentinel- 2 composite of the atmospheric correction and resampling is not $R_{\mathrm{rs}}$, rather than the normalised water-leaving reflectance, $R_{\text {hown }}$ which we converted to $R_{\mathrm{rs}}$ using: 


$$
R_{\mathrm{rs}}=\frac{R_{\text {hown }}}{\pi}
$$

Afterwards, we followed the two-fold pre-processing method of Lee et al. (2001), first, to minimise the possible produced noise from low signals in longer wavelengths than $600 \mathrm{~nm}$ (Red and Vegetation red edge bands for the herein used Sentinel- 2 band set) and, second, to compensate for under- or over-correction of the atmospheric interference by C2RCC. The first part was performed by applying a $3 \times 3$ low-pass filter in the two aforementioned bands. For the second part, if we assume that the product of (2) is $R_{\mathrm{rs}}{ }^{\text {raw: }}$ :

$$
\begin{aligned}
& R_{\mathrm{rs}}^{*}(\lambda)=R_{\mathrm{rs}}^{\mathrm{raw}}(\lambda)-R_{\mathrm{rs}}^{\mathrm{raw}}\left(\lambda_{5}\right) \\
& \Delta=0.0001+0.02 R_{\mathrm{rs}}^{*}\left(\lambda_{4}\right) \\
& R_{\mathrm{rs}}(\lambda)=R_{\mathrm{rs}}^{*}(\lambda)+\Delta
\end{aligned}
$$

This corrected $R_{\mathrm{rs}}$ is then used to invert sub-surface properties.

Following Hydrolight simulations, Lee et al. (1999) approximated optically shallow $R_{\mathrm{rs}}$ with $\varphi=90^{\circ}$ as:

$$
R_{\mathrm{rs}}=\frac{\zeta r_{\mathrm{rs}}}{1-\Gamma r_{\mathrm{rs}}}
$$

where $r_{\mathrm{rs}}$ is the sub-surface remote sensing reflectance, that is the ratio of the water leaving radiance to downwelling radiance just below the water surface. The denominator $1-\Gamma r_{\text {rs }}$ accounts for the internal reflection of the air-water interface, while $\zeta$ is the water-to-air divergence factor (Mobley 1994). The effects of the internal reflection can be large in turbid or very shallow waters and thus are retained here due to the existence of shallow waters $(<1 \mathrm{~m})$ in our survey site. We used $\zeta=0.5$ and $\Gamma=1.5$ after the findings of Morel and Gentili (1993) for remote-sensing observation angles.

$$
\begin{gathered}
r_{\mathrm{rs}}=r_{\mathrm{rs}}^{\mathrm{c}}+r_{\mathrm{rs}}^{\mathrm{b}} \\
\approx r_{\mathrm{rs}}^{\mathrm{dp}}\left[1-\exp \left(-\left(\frac{1}{\cos \left(\theta_{\mathrm{w}}\right)}+\frac{D_{\mathrm{u}}^{\mathrm{c}}}{\cos \left(\theta_{v}\right)}\right) \kappa \mathrm{H}\right)\right] \\
+\frac{1}{\pi} \rho \exp \left(-\left(\frac{1}{\cos \left(\theta_{\mathrm{w}}\right)}+\frac{D_{\mathrm{u}}^{\mathrm{b}}}{\cos \left(\theta_{v}\right)}\right) \kappa H\right)
\end{gathered}
$$

with

$r_{\mathrm{rs}}^{\mathrm{dp}}$, the sub-surface remote sensing reflectance for optically deep waters equalling here:

$$
r_{\mathrm{rs}}^{\mathrm{dp}} \approx(0.084+0.170 u) u
$$

with

$$
\begin{gathered}
u=\frac{b_{\mathrm{b}}}{a+b_{\mathrm{b}}} \\
D_{\mathrm{u}}^{\mathrm{C}} \approx 1.03(1+2.4 u)^{0.5}, \text { and } D_{\mathrm{u}}^{\mathrm{b}} \approx 1.04(1+5.4 u)^{0.5}
\end{gathered}
$$

and, 


$$
\begin{gathered}
\kappa=a+b_{\mathrm{b}} \\
a=a_{\mathrm{w}}+a_{\mathrm{phy}}+a_{\mathrm{g}} \\
b_{\mathrm{b}}=b_{\mathrm{bw}}+b_{\mathrm{bp}}
\end{gathered}
$$

In the above-given set of equations, $D_{\mathrm{u}}{ }^{\mathrm{c}}$ and $D_{\mathrm{u}}{ }^{\mathrm{b}}$ are the optical path-elongation factors for water column and bottom photons, respectively, and are approximated as in Lee et al. (1999). Additionally, $k$ is the attenuation coefficient, $a_{\mathrm{w}}$ is the absorption coefficient of pure seawater, $a_{\text {phy }}$ is the absorption coefficient of phytoplankton pigments, and $a_{\mathrm{g}}$ is the absorption coefficient of gelbstoff and detritus. Additionally, $b_{\mathrm{bw}}$ is the backscattering coefficient of pure seawater and $b_{\mathrm{bp}}$ is the backscattering coefficient of suspended particles. Both $u$ in Equation (7) and $k$ in Equation (9) are inherent optical properties and altogether, the combination of Equations (5)-(11) provides the expression for $R_{\mathrm{rs}}$.

The left term in Equation (6) comprises the path radiance contribution originating in optically deep waters without any bottom signal, while the right term expresses the bottom contribution following attenuation by the two-way path throughout the water column.

2.3.2.2. Parameterisation. We employed the described model of Equation (5) to solve for the benthic reflectance, $r_{\mathrm{rs}}{ }^{\mathrm{b}}$. The retrieval of such sub-surface properties requires the spectral decomposition of Equation (5). As we utilised Sentinel-2A's bands 1-4 in 10-m resolution for all subsequent calculations, Equation (5) is:

$$
\begin{aligned}
& \operatorname{Rrs}\left(\lambda_{4}\right)=f\left[a_{\mathrm{w}}\left(\lambda_{4}\right), a_{\mathrm{phy}}\left(\lambda_{4}\right), a_{\mathrm{g}}\left(\lambda_{4}\right), b_{\mathrm{bw}}\left(\lambda_{4}\right), b_{\mathrm{bp}}\left(\lambda_{4}\right), r_{r s}^{b}\left(\lambda_{4}\right), H\right] \\
& \operatorname{Rrs}\left(\lambda_{1}\right)=f\left[a_{\mathrm{w}}\left(\lambda_{1}\right), a_{\mathrm{phy}}\left(\lambda_{1}\right), a_{\mathrm{g}}\left(\lambda_{1}\right), b_{\mathrm{bw}}\left(\lambda_{1}\right), b_{\mathrm{bp}}\left(\lambda_{1}\right), r_{r s}^{b}\left(\lambda_{1}\right), H\right] \\
& \operatorname{Rrs}\left(\lambda_{2}\right)=f\left[a_{\mathrm{w}}\left(\lambda_{2}\right), a_{\mathrm{phy}}\left(\lambda_{2}\right), a_{\mathrm{g}}\left(\lambda_{2}\right), b_{\mathrm{bw}}\left(\lambda_{2}\right), b_{\mathrm{bp}}\left(\lambda_{2}\right), r_{r s}^{b}\left(\lambda_{2}\right), H\right] \\
& \operatorname{Rrs}\left(\lambda_{3}\right)=f\left[a_{\mathrm{w}}\left(\lambda_{3}\right), a_{\mathrm{phy}}\left(\lambda_{3}\right), a_{\mathrm{g}}\left(\lambda_{3}\right), b_{\mathrm{bw}}\left(\lambda_{3}\right), b_{\mathrm{bp}}\left(\lambda_{3}\right), r_{r s}^{b}\left(\lambda_{3}\right), H\right]
\end{aligned}
$$

To invert Equation (12) and obtain $r_{r s}{ }^{b}$, we implemented an additional series of empirical and semi-analytical equations to mathematically solve for the unknowns and ultimately derive the bottom properties. It is important to note here that we slightly adapted equations, when needed, to match the central wavelengths of Sentinel-2A bands.

The absorption coefficient of phytoplankton pigments, $a_{\text {phy }}(\lambda)$, is estimated using the single-parameter model of Lee (1998):

$$
a_{\text {phy }}(\lambda)=\left[a_{\mathrm{o}}(\lambda)+a_{1}(\lambda) \ln \left(a_{\text {phy }}\left(\lambda_{1}\right)\right] a_{\text {phy }}\left(\lambda_{1}\right)\right.
$$

with $a_{\text {phy }}\left(\lambda_{1}\right)$ yielded by C2RCC processor. Empirically derived values of $a_{\mathrm{o}}$ and $a_{1}$ were taken from Table 2 of Lee et al. (1999).

Following Bricaud, Morel, and Prieur (1981) and Carder et al. (1999), the absorption coefficient of gelbstoff and detritus, $a_{\mathrm{g}}(\lambda)$ is:

$$
a_{\mathrm{g}}(\lambda)=a_{\mathrm{g}}\left(\lambda_{1}\right) e^{-0.015(\lambda-440)}
$$

with $a_{g}\left(\lambda_{1}\right)$ also estimated by C2RCC.

The backscattering coefficient of suspended particles, $b_{\mathrm{bp}}(\lambda)$ equals: 
Table 2. Accuracies of classified reflectance composites.

\begin{tabular}{|c|c|c|c|c|c|c|c|c|c|}
\hline Reflectance & Number of folds & Number of bands & $\mathrm{OA}(\%)$ & SE (\%) & Habitat & PA (\%) & SE (\%) & UA (\%) & SE (\%) \\
\hline \multirow[t]{2}{*}{$R$ toa } & 6 & 3 & 98.81 & 0.55 & NON-PO & 99.68 & 0.22 & 98.42 & 0.56 \\
\hline & & & & & & 97.40 & 6.15 & 99.47 & 0.32 \\
\hline \multirow[t]{2}{*}{$R$ hown } & 6 & 3 & 97.42 & 0.84 & NON-PO & 99.68 & 0.24 & 96.28 & 0.84 \\
\hline & & & & & PO & 93.75 & 7.43 & 99.45 & 0.33 \\
\hline \multirow[t]{2}{*}{$R$ raw rs } & 6 & 3 & 96.83 & 0.87 & NON-PO & 99.04 & 0.31 & 95.96 & 0.88 \\
\hline & & & & & PO & 93.23 & 7.76 & 98.35 & 0.57 \\
\hline \multirow[t]{2}{*}{$R$ rs } & 6 & 3 & 97.42 & 0.84 & NON-PO & 99.68 & 0.24 & 96.28 & 0.84 \\
\hline & & & & & PO & 93.75 & 7.47 & 99.45 & 0.33 \\
\hline \multirow[t]{2}{*}{$r$ rs } & 6 & 3 & 97.42 & 0.84 & NON-PO & 99.68 & 0.24 & 96.28 & 0.84 \\
\hline & & & & & PO & 93.75 & 7.43 & 99.45 & 0.33 \\
\hline \multirow[t]{2}{*}{$r \mathrm{~b}$ rs } & 6 & 3 & 98.02 & 0.73 & NON-PO & 99.68 & 0.23 & 97.19 & 0.74 \\
\hline & & & & & PO & 95.31 & 6.58 & 99.46 & 0.33 \\
\hline
\end{tabular}

$\mathrm{OA}$ is overall accuracy, SE is standard error, PA is producer accuracy and UA is user accuracy. PO represents $P$. oceanica seagrass, while NON-PO represents all other merged classes.

$$
b_{\mathrm{bp}}(\lambda)=b_{\mathrm{bp}}\left(\lambda_{2}\right)\left(\frac{550}{\lambda}\right)^{Y}
$$

with

$$
b_{\mathrm{bp}}(560)=8 R_{\mathrm{rs}}\left(\lambda_{4}\right)
$$

after Dekker et al. (2011). $Y$ expresses the spectral shape parameter of particle backscattering. We used the default value of 0.5 for all the pixels here (Lee et al. 2001).

2.3.2.3. Satellite-derived bathymetry $(S D B)$. The final unknown to be determined before the inversion of bottom reflectance is the water depth, $H$. Estimations of bathymetry in optically shallow waters is vital to decrease reflectance changes which are attributed to variable depth and water column attenuation. Derivation of bathymetry over dense $P$. oceanica seagrass beds can be challenging due to their small reflectance, caused by shading within the canopy (Dekker et al. 2006), which often render the beds to reflect less light than the neighbouring optically deep waters. In addition, these beds may appear deeper than a seabed of higher reflectance (e.g. sand) at the same true depth. Researchers have traditionally derived bathymetry using empirical regression of satellite band ratios (Dierssen et al. 2003; Lyzenga 1978; Mishra et al. 2005; Stumpf, Holderied, and Sinclair 2003; Traganos and Reinartz 2017). Empirical SDB approaches are valid only within the extent of their applied survey site, requires less data processing, however they are expected to be less accurate than semi-analytical and analytical approaches (Brando et al. 2009; Hedley, Roelfsema, and Phinn 2009; Klonowski, Fearns, and Lynch 2007; Lee et al. 1999; Mobley et al. 2005).

Site-specific, empirical SDB algorithms exploit the assumption that the ratio of attenuation coefficients for a pair of two bands remains the same independent of the bottom type and water depth (Lyzenga 1978). Here, we regressed the log-transformed ratio of sub-surface remote sensing coastal aerosol and green reflectance, after Equation (5), against in situ measured depths to develop an exponential relationship:

$$
H=0.4102 e^{1.3814 x}
$$




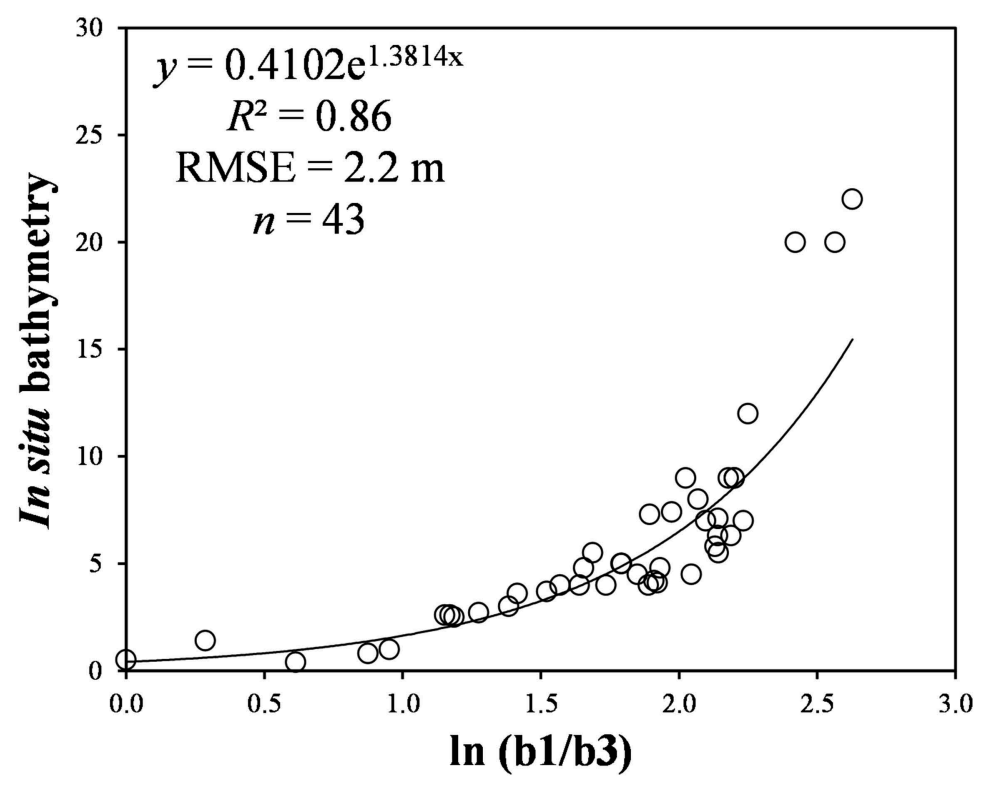

Figure 2. Exponential regression between the log-transformed ratio of sub-surface remote sensing coastal aerosol $(443.9 \mathrm{~nm})$ and green $(560 \mathrm{~nm})$ reflectances, and in situ measured bathymetry from the Thermaikos survey site. The displayed exponential algorithm was used to empirically derived bathymetry in the present study.

$$
x=\ln \left(\frac{r_{\mathrm{rs}}\left(\lambda_{1}\right)}{r_{\mathrm{rs}}\left(\lambda_{3}\right)}\right)
$$

which explained $>86 \%$ of the variation $(p<0.001$ ) in estimated bathymetry in 43 points (Figure 2) between 0.8 and $25 \mathrm{~m}$ with a root-mean-square error (RMSE) of $2.2 \mathrm{~m}$. It is noteworthy that from the 43 points, 2 were over rocky seabed with algae, 4 over Cymodocea nodosa seagrass, 18 over sand, and 19 over Posidonia oceanica seagrass. We employed Equation (17) to estimate $H$ pixel-wise for the optically shallow extent of our survey site, an extent taken from the observations of Traganos and Reinartz (2017). To remove any potential noise resulting from the band rationing, we applied a 5x5 median filter on the SDB result. Finally, we validated the median filtered SDB using 22 additional in situ depth estimations.

\subsubsection{Machine learning-based classification of Posidonia oceanica seagrass beds}

Following the correction of Sentinel-2A bands 1-4 to the benthic reflectance as if the satellite MSI instrument was directly sensing the seabed, we applied the machine learning classifier of Support Vector Machines (SVM) at all six stages of reflectance correction $\left(R_{\text {toar }}\right.$ $\left.R_{\text {hown }}, R_{\mathrm{rs}}{ }^{\text {raw }}, R_{\mathrm{rs}}, r_{\mathrm{rs}}, r_{\mathrm{rs}}{ }^{\mathrm{b}}\right)$ to map the per-pixel distribution of $P$. oceanica seagrass meadows in our survey site and test the contribution of each one of the correction steps. SVM are a group of theoretically superior, universal machine learning algorithms based on the statistical learning theory (Vapnik 1995). The aim of SVM is to differentiate two classes by fitting an optimal hyperplane to the training data of each class in a multi-dimensional space. Support vectors are the data points closer to the separating hyperplane, and they 
are the only ones which define it. Researchers have employed efficiently SVM to solve both linear and, more significantly, non-linear classification problems. In the latter case, the use of a kernel function in a higher dimensional feature space classifies more accurately the training data by the better fit of a linear hyperplane to the new data distribution. In this study, we utilised the Gaussian radial basis function kernel (RBF):

$$
K\left(x_{\mathrm{i}}, x_{\mathrm{j}}\right)=\exp \left(-g x_{\mathrm{i}}-x_{\mathrm{j}}^{2}\right)
$$

where $g$ defines the width of the RBF and $x_{\mathrm{i}}$ and $x_{\mathrm{j}}$ represent feature vectors. Moreover, one has to also specify the regularisation parameter $C$, which regulates the degree of acceptable misclassification errors, hence limiting the influence of particular support vectors. We also conducted a two-dimensional grid search inside a preset range to find an optimal pair of values for $g$ and $C$. The accuracy of this grid search is monitored internally by the k-fold cross-validation.

To classify, validate and test the presence of $P$. oceanica seagrass, we split our initially chosen 2510 pixels (in the forms of polygons), comprising $1.45 \%$ of the whole amount of image pixels, into three parts: (a) the training set, where we parameterised multiple SVM algorithms, (b) the cross-validation set, where the parameterised algorithms of (a) were cross-validated based on their performance, with the best performing being chosen, and finally, c) the test set, where the best performing SVM algorithm was tested for its accuracy on the whole image. Both the training and cross-validation set contained $80 \%$ of the 2510 pixels with the number of cross-validation folds, $k$, determining the final amount of both sets. For example, if $\mathrm{k}$ is 4 , then with the $80 \%$ of the pixels allocated for the training and cross-validation phase, the latter will employ $20 \%$ (80/4) for every internal cross-validation, while the former will employ the remaining $60 \%$. The test set used the remaining $20 \%$ of the pixels. Following Finally, we ran all SVM experiments using the LIBSVM library (Chang and Lin 2013) in EnMAP-Box (van der Linden et al. 2015).

We evaluated the SVM classification results (presence/absence of $P$. oceanica seagrasses) using overall (OA), producer (PA) and user accuracies (UA) per class. While PA is an important statistical metric for the scientist who creates the habitat map, UA is more vital towards the management of the region under study as it provides a quantitative probability of the actual presence of a mapped habitat in this region i.e. P. oceanica seagrass beds.

\section{Results}

\subsection{Water column properties}

The first step towards the retrieval of bottom properties and the mapping of the extensive Posidonia oceanica seagrass meadows in the waters of the Thermaikos Gulf was the pixelwise inversion of water column properties from a Sentinel-2A satellite image, sensed on the 30 March 2017. In the implemented semi-analytical inversion for optically shallow waters (Lee et al. 1998, 1999), both downward and upward diffuse attenuation coefficients, are explicitly expressed as functions of the absorption, $a$, and backscattering, $b_{\mathrm{b}}$, coefficients.

As regards to individual absorption coefficients, for a solar zenith angle of $38.75^{\circ}$ and a wind speed of approximately $0.9 \mathrm{~m} \mathrm{~s}^{-1}, a_{\text {phy }}\left(\lambda_{1}\right)$, the absorption coefficient of phytoplankton pigments at the coastal aerosol wavelength of S2-A, employed to estimate $a_{\text {phy }}$ at all other herein used wavelengths, ranged between 0 and $1.84 \mathrm{~m}^{-1}$ in the optically shallow waters of 
the Thermaikos Gulf (Figure 3(a)). The absorption coefficient of gelbstoff and detritus at $443.9 \mathrm{~nm}, a_{\mathrm{g}}\left(\lambda_{1}\right)$, used to derive $a_{\mathrm{g}}$ at all other used wavelengths (Equation 14), spanned the 0-5.52 $\mathrm{m}^{-1}$ range (not shown here). Along with $a_{\mathrm{w}}$ absorption coefficient of pure seawater, values of $0.0075 \mathrm{~m}^{-1}, 0.0191 \mathrm{~m}^{-1}, 0.0619 \mathrm{~m}^{-1}$ and $0.429 \mathrm{~m}^{-1}$ at the respective, first four S2-A band wavelengths, we calculated the total absorption coefficients, $a$ after Equation (9), which were $0.01-5.53 \mathrm{~m}^{-1}$ at $443.9 \mathrm{~nm}, 0-6.5 \mathrm{~m}^{-1}$ at $496.6 \mathrm{~nm}, 0.062-1.09 \mathrm{~m}^{-1}$ at $560 \mathrm{~nm}$, and, finally, $0.43-1.94 \mathrm{~m}^{-1}$ at $664.5 \mathrm{~nm}$.

On the other hand, concerning individual backscattering coefficients, $b_{\mathrm{bp}}\left(\lambda_{3}\right)$, the backscattering coefficient of suspended particles at the green S2-A wavelength, which was utilised in Equation (15) to derive all other $b_{\mathrm{bp}}$ (Figure 3(b); Equation (16)) ranged between 0 and $0.12 \mathrm{~m}^{-1}$. With estimated $b_{\mathrm{bw}}$ values of $0.0037 \mathrm{~m}^{-1}, 0.0023 \mathrm{~m}^{-1}, 0.0014 \mathrm{~m}^{-1}$ and $0.0006 \mathrm{~m}^{-1}$ at respective S2-A coastal aerosol, blue, green and red wavelengths (Morel 1974), we derived the total backscattering coefficients, $b_{\mathrm{b}}$ after Equation (11), between 0.01 and $0.14 \mathrm{~m}^{-1}$ at 443.9 $\mathrm{nm}, 0-0.13 \mathrm{~m}^{-1}$ at $496.6 \mathrm{~nm}, 0-0.12 \mathrm{~m}^{-1}$ at $560 \mathrm{~nm}$, and, finally, $0-0.11 \mathrm{~m}^{-1}$ at $664.5 \mathrm{~nm}$.

Following estimations of both absorption and backscattering coefficients, we derived their pixel-wise sum, $k$, attenuation coefficient in the optically shallow extent of the Thermaikos Gulf, which ranged between 0.01 and $5.58 \mathrm{~m}^{-1}$ at $443.9 \mathrm{~nm}$ (Figure 3(c)), 06.49 at $496.6 \mathrm{~nm}$ (produced by C2RCC), 0.06-1.2 nm at $560 \mathrm{~nm}$, and 0.43-2.04 at $664.5 \mathrm{~nm}$.

In addition to $k$, calculation of $a$ and $b_{\mathrm{b}}$, yielded $u$, an important inherent optical parameter, after Equation (7), towards the derivation of both the ranges of optical path-elongation factors for water column and bottom photons, $D_{\mathrm{u}}{ }^{\mathrm{c}}$ and $D_{\mathrm{u}}{ }^{\mathrm{b}}$, respectively (Equation 8) and $r_{\mathrm{rs}}{ }^{\mathrm{dp}}$, the sub-surface remote sensing reflectance for optically deep waters (Equation 6). The values of $D_{\mathrm{u}}{ }^{\mathrm{c}}$ and $D_{\mathrm{u}}{ }^{\mathrm{b}}$ were 1.03-2.14 and 1.4-3.03 in all bands, correspondingly. Median $r_{\mathrm{rs}}{ }^{\mathrm{dp}}$ values over 96581 optically deep water pixels were $0.05 \mathrm{sr}^{-1}, 0.007 \mathrm{sr}^{-1}, 0.004 \mathrm{sr}^{-1}$ and $0.0006 \mathrm{sr}^{-1}$ at coastal aerosol, blue, green and red central wavelengths, respectively.

\subsection{Satellite-derived bathymetry}

We used the site-specific exponential algorithm of Equations (17)\&(18) to empirically derive pixel-wise bathymetry, $H$, of the optically shallow extent of our survey site in the Thermaikos Gulf (Figure 4); the mean depth of the Gulf is $10.98 \mathrm{~m}$. We validated the $5 \times 5$ median filtered SDB using 22 in situ measurements (of the initial 65 points). These measurements revealed a coefficient of determination $\left(R^{2}\right)$ value of 0.48 with an RMSE of $3.67 \mathrm{~m}$ over the whole optically shallow extent (Figure 5).

\subsection{Benthic reflectance}

Employing Equations (5)-(18), we performed the pixel-wise, semi-analytical inversion of bottom properties, videlicet, water column correction, of the $10 \mathrm{~m} /$ pixel coastal aerosol, blue, green and red S2-A bands in the optically shallow waters of the Thermaikos Gulf. This mixture of empirical and semi-analytical equations derived optical water column constituents and water depth per pixel which were used in turn as inputs to output pixel-wise bottom reflectance, $r_{\mathrm{rs}}{ }^{\mathrm{b}}$, in 173559 pixels (Figure 6(a)). The retrieved $r_{\mathrm{rs}}{ }^{\mathrm{b}}$ were $0-0.02 \mathrm{sr}^{-1}$ at $443.9 \mathrm{~nm}, 0.001-0.04 \mathrm{sr}^{-1}$ at $496.6 \mathrm{~nm}, 0.005-0.076 \mathrm{sr}^{-1}$ and $0.01-0.04 \mathrm{sr}^{-1}$ at $664.5 \mathrm{~nm}$ over all optically shallow habitats. 


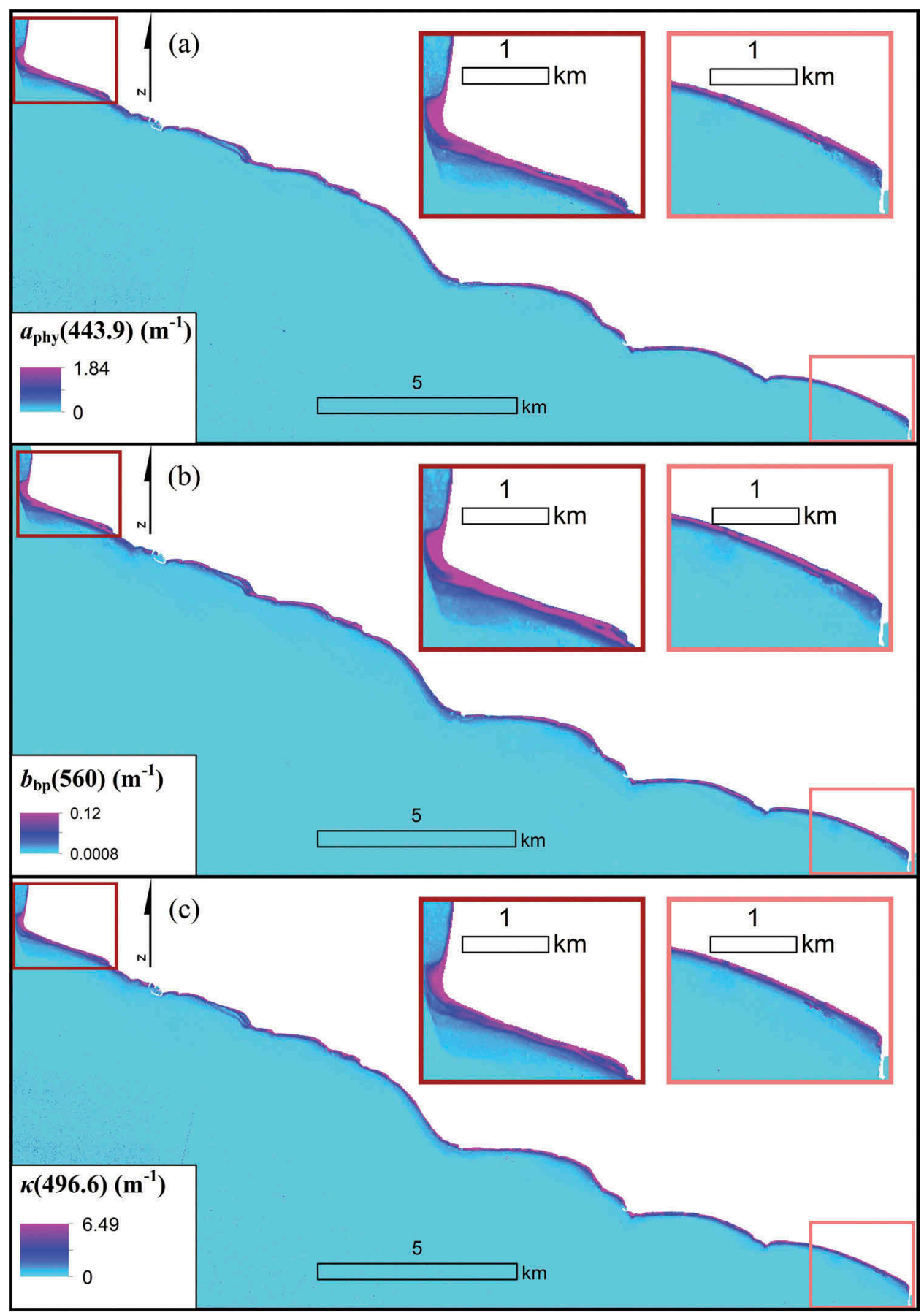

Figure 3. Examples of retrieved inherent parameters from both C2RCC and the herein parameterised HOPE (Lee et al. 1999) model in the Thermaikos Gulf (see Figure 1). (a) Absorption coefficient of phytoplankton pigments at $443.9 \mathrm{~nm}$, (b) Backscattering coefficient of suspended particles at $560 \mathrm{~nm}$, (c) Attenuation coefficient at $496.6 \mathrm{~nm}$. 


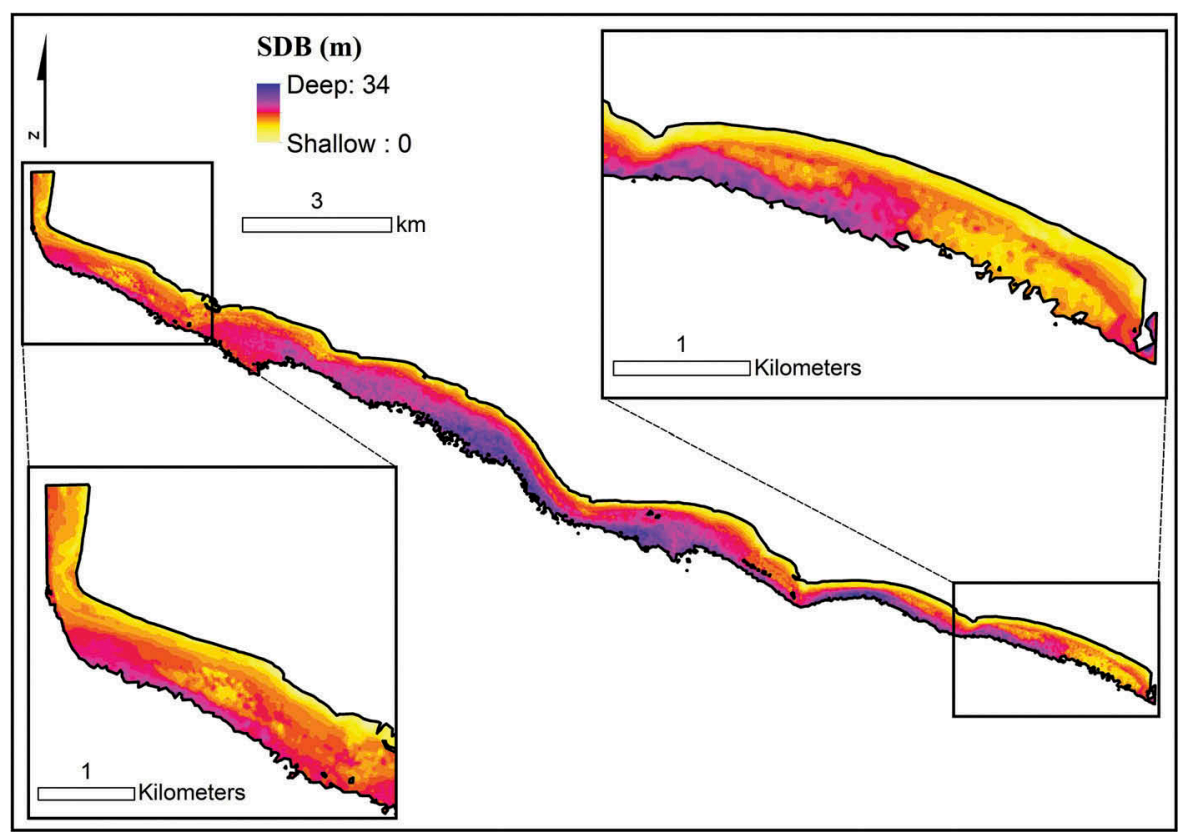

Figure 4. $5 \times 5$ median-filtered, Satellite-derived bathymetry $(\mathrm{H})$ of the Thermaikos Gulf (see Figure 1) based on the empirical regression of Equations (17)-(18) shown in Figure 2. The displayed extent follows the application of an optically shallow mask until $16 \mathrm{~m}$ after Traganos and Reinartz (2017).

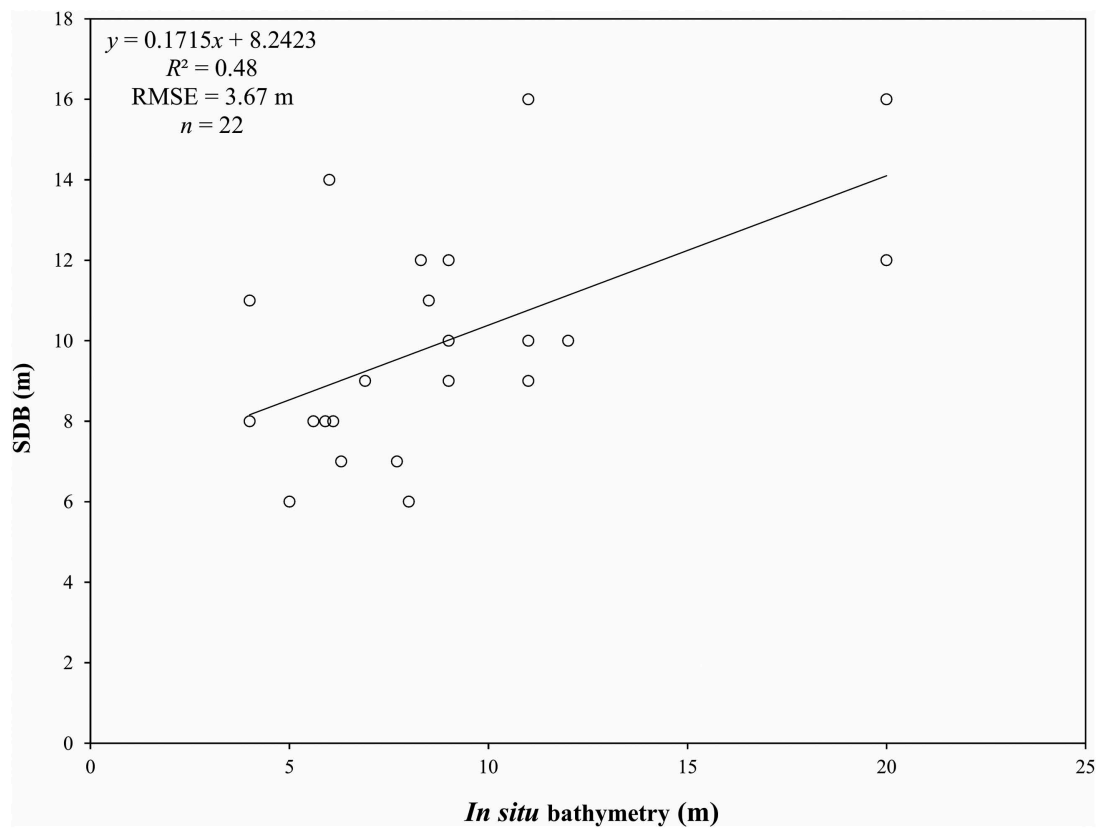

Figure 5. Validation of the Satellite-derived Bathymetry $(\mathrm{H})$ shown in Figures 2 and $4 . \mathrm{H}$ was utilised in Equation (5) to invert bottom reflectances. 


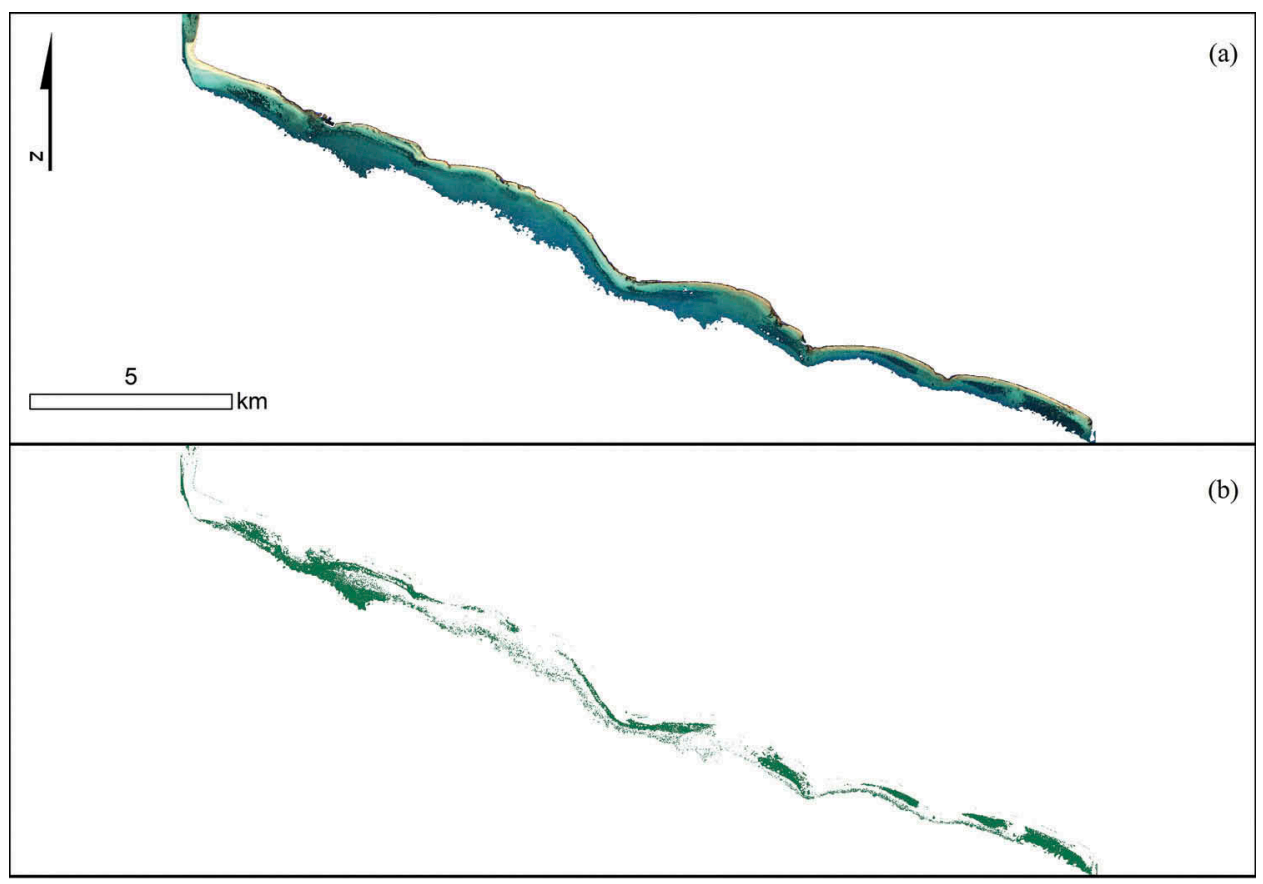

Figure 6. Machine-learning-based classification of P. oceanica seagrass-shown in green in panel (b)-bottom reflectances. Accuracy assessment is shown in Table 2.

\subsection{Machine learning-based classification of Posidonia oceanica seagrass beds}

Figure 6 shows the classified by SVM reflectances (3-band composites, 6 -fold cross validation) of $P$. oceanica seagrass meadows at the bottom reflectance stage. The respective accuracy assessment is provided in Table 2 . In terms of all stages of reflectance correction, however, the best performing classification was surprisingly the $R_{\text {toa }}$ composite with an overall accuracy of $98.8 \%$ (0.55\% standard error), and PO producer and user accuracy of $97.4 \%$ and $99.47 \%$, respectively. It was followed by $r_{\mathrm{rs}}{ }^{\mathrm{b}}$ which featured decreased OA, PA and UA of $0.79 \%$ (lower $0.15 \%$ standard error), $2.09 \%$ and $0.01 \%$, respectively. We observe that the raw above-surface remote sensing reflectance, $R_{\mathrm{rs}}{ }^{\mathrm{raw}}$ exhibited the lowest accuracies, while in comparison, the corrected for atmospheric interference one, $R_{\mathrm{rs}}$ and the subsurface remote sensing reflectance, $r_{\mathrm{rs}}$ were both $0.59 \%, 0.52 \%$ and $1.1 \%$ more accurate in terms of $\mathrm{OA}, \mathrm{PA}$ and $\mathrm{UA}$, correspondingly.

Following the elaboration on the split between training and cross-validation data in the second paragraph of 2.3.3., the 6-fold cross-validation means that from the $80 \%$ of the data which were allocated for training and cross-validating the individual SVM algorithm, $67 \%$ was used for the former and the remaining $13 \%$ for the latter step.

Optically shallow remote sensing of the Thermaikos Gulf using Sentinel-2A imagery revealed eight dense $P$. oceanica seagrass meadows which cover an area of $\sim 300$ ha between 2 and $16 \mathrm{~m}$. PO beds, therefore, occupied $17.3 \%$ of the optically shallow extent of the survey site.

Given herein implemented polygons for the machine learning-based classification of $P$. oceanica seagrass habitat, we extracted 320 pixel values over this particular habitat 


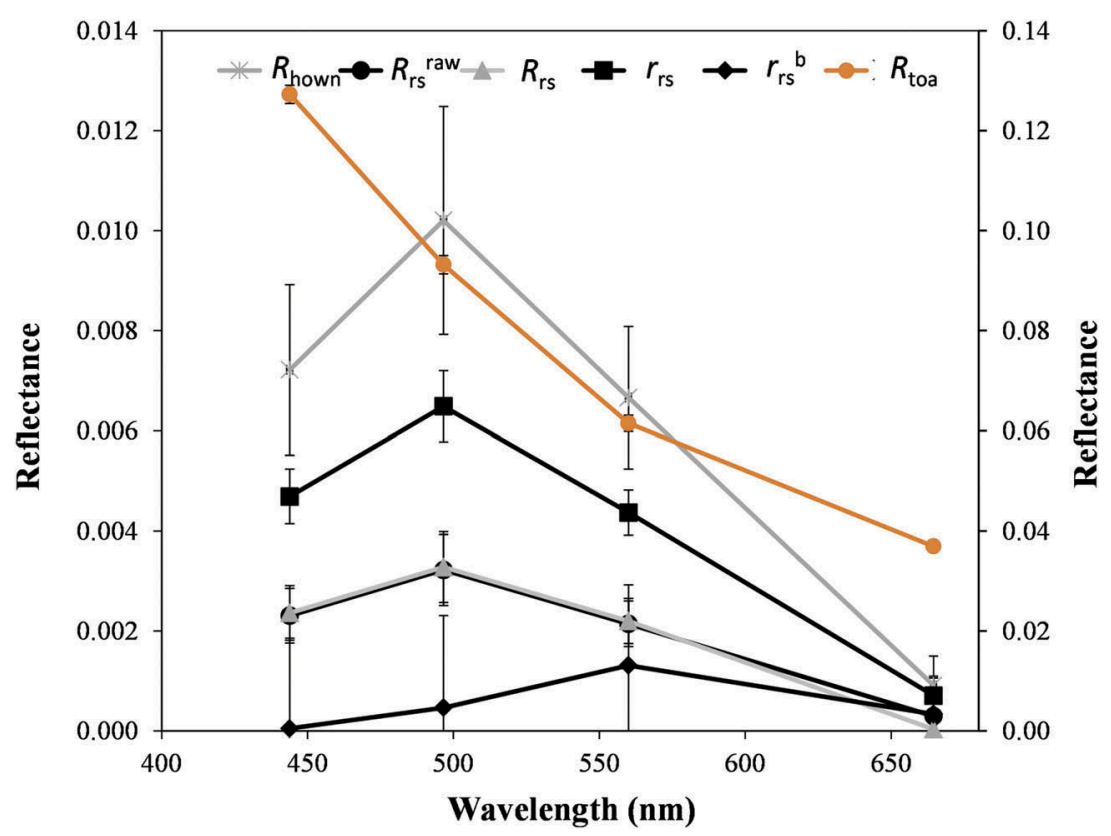

Figure 7. Mean spectral reflectances (plus standard deviation) over 320 pixels of classified as $P$. oceanica seagrass beds for the four first bands of Sentinel-2A (all in $10 \mathrm{~m} /$ pixel resolution) for all the estimated products in the present study. Description of reflectance denominators are provided in section 2.3.2. The secondary y-axis displays reflectance values only for the Rtoa.

from all the produced reflectance composites of the present study (e.g. $R_{\mathrm{toa}}, R_{\text {hown }}, R_{\mathrm{rs}}{ }^{\text {raw }}$, $R_{\mathrm{rs}}, r_{\mathrm{rs}}, r_{\mathrm{rs}}{ }^{\mathrm{b}}$ ) (Figure 7). We show Figure 7 to aid understanding of the spectral behaviour of $P$. oceanica-vegetated seabed across the relevant to optically shallow remote sensing spectrum and relevant corrections. There are several notable characteristics in Figure 7:

(1) All corrections between the toa and bottom layers featured a reflectance peak at $496.6 \mathrm{~nm}$ and decay towards the $664.5-\mathrm{nm}$ wavelength.

(2) The benthic reflectance of PO peaked at $560 \mathrm{~nm}$, while was nearly equal at the S2A blue and red central wavelengths.

(3) $r_{\mathrm{rs}}{ }^{\mathrm{b}}$ ranged from $0.03 \%$ of the $R_{\text {toa }}$ at the coastal aerosol wavelength to $2.1 \%$ of it at the green wavelength.

(4) PO reflectances at all levels were lower than $12.7 \%$ of the initial remote sensing signal.

We also show the mean reflectance of Posidonia oceanica seagrass and other co-existing habitats (Cymodocea nodosa seagrass, photophilous algae and deep water) for the produced reflectance composite of $r_{\mathrm{rs}}{ }^{\mathrm{b}}$ ) (Figure 8). Habitats in our survey site exhibited different peaks, troughs and variable reflectance across the Sentinel-2 bands which allows their more accurate machine learning-based discrimination. 


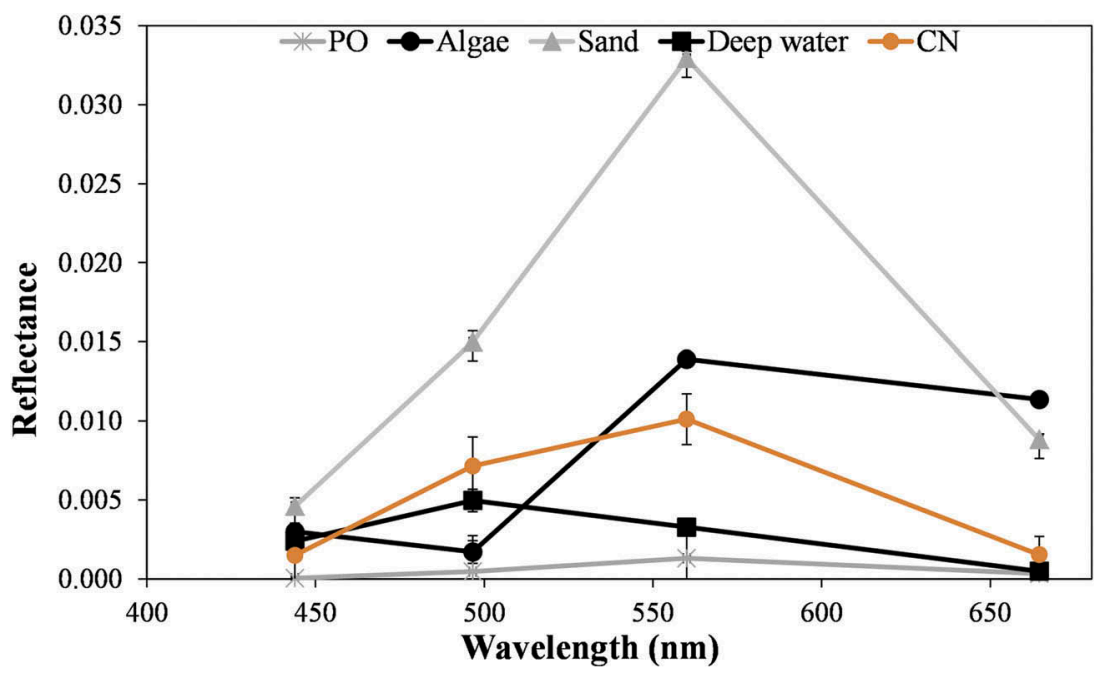

Figure 8. Mean spectral reflectances of the classified habitats for the four first bands of Sentinel-2A (all in $10 \mathrm{~m} /$ pixel resolution) for bottom reflectance product. PO and CN represent Posidonia oceanica and Cymodocea nodosa seagrasses, respectively.

\section{Discussion}

Our main objective in this study was to evaluate the suitability of the Sentinel-2 satellite to quantitatively derive benthic reflectance as well as the distribution of the endemic and dominant in the Mediterranean P. oceanica seagrass meadows between 0-16m in 1736 optically shallow hectares of the Thermaikos Gulf, NW Aegean Sea, Greece. To reach our objective, we employed a methodological workflow which included atmospheric and airwater interface correction, resampling of the implemented lower resolution Sentinel-2 bands, satellite-derived bathymetry using an empirical site-specific ratio, semi-analytical inversion of optical water column constituents and bottom reflectance (Lee et al. 1998, 1999) and, finally, the machine learning algorithm of Support Vector Machines (Vapnik 1995).

\subsection{Sentinel-2 suitability for $\boldsymbol{P}$. oceanica seagrass mapping}

Ideally, mapping approaches in optically shallow waters, as the herein studied site, should involve suitable atmospheric, air-water interface and water column corrections to derive bottom reflectance prior to the classification step. Here, the SVM classifier on S2-A coastal aerosol, blue, green red bottom reflectances showed a very high producer accuracy of $97.4 \%$ and user accuracy of $99.47 \%$ on a two-class problem (presence or absence of $P$. oceanica beds) with an RBF kernel and a 6-fold cross-validation. SVM yielded more accurate results following classification of the $R_{\text {toa }}$ composite, namely prior to any correction of the reflectance, while the classified benthic reflectance composite, $R_{\mathrm{rs}}{ }^{\mathrm{b}}$ yielded the second best observed accuracies. This observation raises questions about the necessity of correcting the top-of-atmosphere to the benthic reflectance when one does not need accurate retrieval of the latter-in contrast to the case of forward modelling or existence of accurate field data for optimisation approaches - rather than an accurate classification of the extent of benthic habitat. We assume that application of the same workflow on a different Sentinel-2 or other 
multispectral/hyperspectral image would produce increasing efficiency from stages 1 to 6 of the successive reflectance corrections. Nevertheless, the herein utilised workflow for $P$. oceanica mapping produced accuracies (OA, PA, UA) greater than $93 \%$ at all stages of reflectance correction (Table 2 ).

The small misclassification between the two classes could be attributed to mixed pixels of any of the three following types: a) P. oceanica seagrass and sand (near or on top of seagrass canopy), (b) $P$. oceanica and Cymodocea nodosa seagrass, which is also studied near the meadows of the former (Traganos and Reinartz (2017), and c) P. oceanica seagrass and optically deep seabed due to the low reflectance of the former and the inclusion of the latter in the implemented optically shallow mask here. We applied the optically shallow mask following previous findings concerning the depth range of $P$. oceanica presence (Traganos and Reinartz 2017). More accurate approaches as the Substratum Detectability Index implemented in the SAMBUCA semi-analytical model (Brando et al. 2009) could have provided better discrimination between optically shallow and deep pixels, and thus mapping of the aquatic habitats in study. Polygons utilised for training, cross-validation and test of SVM were extracted by interpretation of the presence/absence of $P$. oceanica seagrass meadows on the processed S2-A imagery.

In this study, we paired the machine learning of SVM with the semi-analytical model of HOPE to retrieve the benthic extent of seagrass in a Mediterranean Gulf with neighbouring habitats of high variation in their reflectance (shallow sands of high reflectance to deep seagrasses of low reflectance). Modifying the benthic reflectance parameterisation of HOPE, BRUCE semi-analytical model (Klonowski, Fearns, and Lynch 2007) retrieves benthic cover of three substrates (seagrass, sediment and brown algae) along with bathymetry by spectral matching of modelled and image reflectances. While we did not test the applicability of BRUCE model and/or compare it to the SVM approach here, we expect the adaption and estimation of four-component bottom reflectance fractions to improve accuracies of our methodological workflow.

In general, machine learning-based mapping approaches in the remote sensing of optically shallow habitats are rare. In one of these SVM and RF (Random Forests)-based approaches, also directly comparable to the present study, due to the same underwater setting (Thermaikos Gulf) and satellite imagery, the best observed accuracies were somewhat similar (94.4\% overall accuracy, 100\% producer accuracy, $94.8 \%$ user accuracy), albeit using an almost 10-fold smaller set of training and test pixels ( 228 vs 2510 pixels here) in a smaller optically shallow extent (three vs eight meadows here). This last observation about the amount of training data comes in line with the findings that SVM define well the hyperplane even from a small number and/or data quality (Mountrakis, Im, and Ogole 2011). SVM defines the hyperplane allocating only the support vectors from the whole amount of the training data. To achieve higher accuracies, therefore, one has to select suitable data points which are likely to be support vectors rather than a large data set. This is exemplified by the observed ratios of support vectors to the total amount of training data in use in our study and the study in comparison (Traganos and Reinartz 2017). In our approach, only $4.7 \%$ of the training data in use are support vectors, while in the latter the respective ratio is $45.9 \%$ on a nearly 25 times smaller training set. It is noteworthy that the training data set in our study consisted of polygons (set of pixels) rather than individual pixels as in Traganos and Reinartz (2017). 
In another application in the same coastal environment of the Thermaikos Gulf, SVM yielded an overall accuracy of $68.1 \%$, producer accuracy of $95.1 \%$, and a user accuracy of 70.9\% using Planet's multispectral CubeSat-derived imagery and the empirical water column correction of Lyzenga (1978) (Traganos and Reinartz 2017). This highlights the issue of SVM with noisy data, such as the Planet's CubeSat-derived imagery over coastal areas, as they are algorithms not optimised to deal with this problem (Mountrakis, Im, and Ogole 2011). SVM performance in Traganos, Cerra, and Reinartz (2017) increased by the use of the Unmixing-based Denoising (UBD) which has also shown remarkable improvements in hyperspectral scenes over coastal waters (Cerra et al. 2013, 2017). Elsewhere, Eugenio, Marcello, and Martin (2015) employed SVM algorithm with an RBF kernel in a similarly parameterised radiative transfer model to ours to map benthic habitats on a WorldView- 2 with an overall accuracy of $73 \%$ in a depth range between $0-25 \mathrm{~m}$.

\subsection{Sentinel-2 suitability for inverting water column properties, bathymetry and benthic reflectance in optically shallow waters}

The initial model-driven spectral optimisation technique of HOPE (Lee et al. 1998, 1999) simultaneously retrieves optical water column properties and water depth. Here, we simplified its radiative transfer equations to derive water column and bottom properties from a Sentinel-2 image, while we estimated bathymetry using an empirical regression. The simplification is required due to the limited spectral bands of S2 in comparison to the initially 16 bands between $400-700 \mathrm{~nm}$ implemented in the development of HOPE. Moreover, the central wavelengths of S2 bands are slightly different than the utilised wavelengths in the initial radiative transfer equations (e.g. $560 \mathrm{~nm}$ for S2-A band 3 vs $550 \mathrm{~nm}$ in the $b_{\mathrm{bp}}\left(\lambda_{3}\right)$ coefficient) which is expected to be a source of error here. Lack of relevant in situ data constrained the assessment of the retrieval error of resulting water column and bottom properties-produced either by C2RCC or the empirical equations. As regards to the atmospheric and in-water processor C2RCC, it is mainly used as the ground segment processor of the Sentinel $3 \mathrm{OLCl}$ for generating Case 2 water-related products and also in the MERIS $4^{\text {th }}$ reprocessing. Toming et al. (2017) has utilised it to map water-leaving reflectance, IOPs and water quality parameter (e.g. chlorophyll $a$, suspended matter and dissolved organic matter) in the optically complex Baltic Sea from Sentinel-3 data; they reported realistic spectra for the yielded water leaving reflectance in contrast to bad correlations of the IOPs and water quality parameters with in situ data.

Concerning the optical water column properties, derived $k\left(\lambda_{2}\right)$ (Figure 3(c)) by C2RCC displayed higher values (maximum of $6.49 \mathrm{~m}^{-1}$ ) and much greater variation in the optically shallow waters of the Thermaikos Gulf near the terrestrial part than the bottom portion of the Sentinel-2 image which comprise optically deep waters. This behaviour is normal as $k$ is the sum of $a$, the total absorption coefficient and $b_{\mathrm{b}}$, the total backscattering coefficient, and these optical parameters tend to be higher and to strongly vary near the terrestrial side due to the river runoff (Figure 1) and higher backscattering of possibly suspended sand particles of the underlying seabed. Additionally, the mean $k$ $\left(\lambda_{2}\right)$ of $0.044 \mathrm{~m}^{-1}$ is somewhat lower than the image-derived $0.067 \mathrm{~m}^{-1}$ of Traganos and Reinartz (2017) for the same waters. All in all, the existence of relevant field data could further resolve the accuracy of the produced parameters by C2RCC. 
Regarding the satellite-derived bathymetry, $H$, we estimated a $10-\mathrm{m}$ pixelwise bathymetry map of our survey site using an empirical regression between the super-resolved to $10 \mathrm{~m} /$ pixel coastal aerosol and the green sub-surface remote sensing reflectance, $r_{\mathrm{rs}}$. We utilised the coastal aerosol instead of the previously implemented blue band (Traganos and Reinartz 2017) to exploit its greater penetration in the optically shallow water column. Studies related to SDB approaches have shown that sensors with bands centred around $443 \mathrm{~nm}$ yield more accurate results in contrast to those lacking a similar spectral band (Collin et al. 2012; Pacheco et al. 2015). On the other hand, we should note two inherent issues in empirical SDB approaches over optically shallow environments with dense seagrass meadows as in the Thermaikos Gulf. The first issue is related to the contribution of the underlying low reflectance of seagrass to the SDB which is apparently large. This issue is two-fold: a) First, it causes an overestimation of SDB due to the somewhat failure of the herein implemented ratio to minimise seagrass contribution, and (b) As we implemented an optically shallow mask between $0-16 \mathrm{~m}$, following the findings of Traganos and Reinartz (2017), this is expected, according to point (a), to include optically deep pixels in the mask which could cause misclassification in the detection of $P$. oceanica seagrass due to the marginal difference between the beds of the latter and neighbouring optically deep waters. The second issue is more general and is related to the inherent errors due to the simple nature of the empirically derived bathymetry in comparison to more sophisticated semi- or analytical derivations. Nonetheless, the empirical approach provides a time- and costefficient way for estimating SDB given existence of a set of accurate in situ bathymetry measurements (Dierssen et al. 2003; Stumpf, Holderied, and Sinclair 2003).

Finally, concerning the suitability of Sentinel-2A to invert benthic reflectances, quantitative assessment (Figure 7) reveals that our processing chain succeeded in retrieving the characteristic spectrum shape for seagrass species presented elsewhere (Fyfe 2003; Thorhaug, Richardson and Berlyn, 2005). In contrast to the correct spectral shape, the magnitude at all four herein wavelengths was nearly ten-fold less at $443.9 \mathrm{~nm}, 50 \%$ lower at $496.6 \mathrm{~nm}$, seven times less at $560 \mathrm{~nm}$, and nearly twice as low at $664.5 \mathrm{~nm}$ in comparison to the reported magnitudes of Thornhaug, Richardson and Berlyn (2005). Inversion methods like the algorithm of Lee et al. $(1998,1999)$ may produce incorrect results due to uncertainties related to the estimation of certain parameters, uncertainties that propagate to the output. Moreover, the assumption of horizontal homogeneity of optical water column parameters by HOPE could produce inaccurate results (Lee et al. 2007). Also, pre-processing steps like the selected atmospheric and sun glint corrections could possibly impact HOPE results (Goodman and Ustin, 2007).

A few studies have used the inversion scheme of HOPE to accurately derive water column and bottom properties, and water depth simultaneously (Goodman and Ustin 2007; Lee et al. 2001, 2007; Mishra et al. 2005). Goodman and Ustin (2007) employed a hyperspectral AVIRIS imagery of Kaneohe Bay, Hawaii to examine impacts of pre-processing methods (atmospheric and sun glint correction) on a HOPE-based retrieval of four bottom types (sand, coral, algae and flat spectrum). Lee et al. (2001) used the same type of hyperspectral imagery over Tampa Bay, Florida in a HOPE implementation over two types of bottom: sand and seagrass. Finally, Lee et al. (2007) successfully mapped optical parameters, bottom reflectance and bathymetry over a single sandy bottom using EO-1 Hyperion data over Looe Key, Florida, while Mishra et al. (2005) mapped sand, seagrass and corals at the Roatan Island, Honduras using a simplified version of HOPE adapted to IKONOS data to derive an overall accuracy of $80.6 \%$. 


\subsection{Seagrasses in the epoch of Analysis Ready Data (ARD) and climate change}

In the human-induced climate change era, seagrasses should be awarded a more central role mainly due to their ability to act as a natural carbon capture technology (Fourqurean et al. 2012). There are existing gaps as regards to the large-scale quantification of the $\mathrm{CO}_{2}$ absorption by seagrasses. This is immediately related to SDG 13 ('Take urgent action to combat climate change and its impacts') and SDG 14 ('Conserve and sustainably use the oceans, seas and marine resources for sustainable development') (UN 2017). To achieve both these goals, and thus to derive quantitative information on the carbon absorption and other biophysical parameters indicative of seagrass ecosystem services and health, remote sensing can be one of the most vital elements in the toolbox of ocean science. This is attributed to the capability of the remote sensing technologies to time- and cost-efficiently measure numerous parameters in a non-intrusive manner and high spatio-temporal scale. Recent advances in the development of new multispectral satellites (i.e. Sentinel series, Landsat-8, WorldView series, Planet's Doves), cloud computing platforms (the already launched Google Earth Engine and the soon-to-be-launched DIAS-Copernicus Data and Information Services), machine and deep learning algorithms could all aid high spatiotemporal, large-scale mapping and monitoring of seagrass habitats (Traganos et al. 2018b) which would galvanise two things: a) better management and conservation practices, and (b) the integration of seagrasses to the epoch of Analysis Ready Data (ARD) and sensoragnostic approaches where satellite data will be already pre-processed to an already high scientific standard and offered as science-ready data immediately after being imaged by a single sensor (Catapult 2017; Collison and Wilson 2017; Landsat 2017) or by multiple sensors (Descartes Labs 2017). These approaches will decrease the required processing time of satellite data, will increase their usability by a greater number of non-remote sensing experts and will finally enable physical change of relevant parameters to seagrass habitats and coastal ecosystems to be indexed much alike how Google has indexed the Internet.

\section{Acknowledgments}

Dimosthenis Traganos is supported by a DLR-DAAD Research Fellowship (No. 57186656). We thank ESA for providing Sentinel-2A data through the Sentinels Scientific Data Hub. EnMap-Box software is provided for free under the EnMAP Open Source Licence. We thank the two anonymous reviewers who have significantly improved the quality of the present paper.

\section{Funding}

This work was supported by the Deutscher Akademischer Austauschdienst [DLR-DAAD Research Fellowship No. 57186656];

\section{ORCID}

Dimosthenis Traganos (D) http://orcid.org/0000-0003-0766-7986 


\section{References}

Barillé, L., M. Robin, N. Harin, A. Bargain, and P. Launeau. 2010. "Increase in seagrass distribution at Bourgneuf Bay (France) detected by spatial remote sensing." Aquatic Botany 92: 185-194. doi:10.1016/j.aquabot.2009.11.006.

Bonacorsi, M., C. Pergent-Martini, N. Bréand, and G. Pergent. 2013. "Is Posidonia oceanica regression a general feature in the Mediterranean Sea?" Mediterranean Marine Science 14: 193-203. doi:10.12681/mms.334.

Borfecchia, F., L. D. Cecco, S. Martini, G. Ceriola, S. Bollanos, G. Vlachopoulos, L. M. Valiante, et al. 2013. "Posidonia oceanica genetic and biometry mapping through high-resolution satellite spectral vegetation indices and sea-truth calibration." International Journal of Remote Sensing 34 :4680-4701. doi:10.1080/01431161.2013.781701.

Brando, V. E., J. M. Anstee, M. Wettle, A. G. Dekker, S. R. Phinn, and C. Roelfsema. 2009. "A physics based retrieval and quality assessment of bathymetry from suboptimal hyperspectral data." Remote Sensing of Environment 113: 755-770. doi:10.1016/j.rse.2008.12.003.

Bricaud, A., A. Morel, and L. Prieur. 1981. "Absorption by dissolved organic matter of the sea (yellow substance) in the UV and visible domains." Limnology and Oceanography 26 (1): 43-53. doi:10.4319/lo.1981.26.1.0043.

Brockmann, C., R. Doerffer, P. Roland, M. Peters, K. Stelzer, S. Embacher, and A. Ruescas. 2016. "Evolution of the C2RCC neural network for Sentinel 2 and 3 for the retrieval of ocean colour products in normal and extreme optically complex waters." In Living Planet Symposium, Proceedings of the conference held in May, 9-13 May 2016, edited by L. Ouwehand, Prague, Czech Republic: European Space Agency. ESA-SP Volume 740.

Carder, K. L., F. R. Chen, Z. P. Lee, and S. K. Hawes. 1999. "Semi-analytic moderate resolution imaging spectrometer algorithms for chlorophyll a and absorption with bio-optical domains based on nitrate-depletion temperatures." Journal of Geophysical Research 104: 5403-5421. doi:10.1029/1998JC900082.

Catapult. 2017. "Sentinel-2 Analysis Ready Data: Standards and automated production." Accessed December 21 2017. https://media.sa.catapult.org.uk/wp-content/uploads/2017/07/09123212/ Outputs-Sentinel-2-part-2-v0.2.pdf?lipi=urn\%3Ali\%3Apage\%3Ad_flagship3_pulse_read\% 3BV1gVuKIFQbu0zMOmea6Qrw\%3D\%3D

Cerra, D., D. Traganos, P. Gege, and P. Reinartz. 2017. "Unmixing-based Denoising as a preprocessing step for Coral Reef Analysis." In The International Archives of the Photogrammetry, Remote Sensing and Spatial Information Sciences, Volume XLII-1/W1. Hannover: ISPRS. doi:10.5194/isprs-archives-XLII-1-W1-279-2017

Cerra, D., P. Gege, R. Müller, and P. Reinartz. 2013. "Exploiting noisy hyperspectral bands for water analysis." 33th EARSeL Symposium Proceedings, Matera, Italy, June 3-6, 43-48.

Chang, C., and C. Lin. 2013. "LIBSVM: a library for support vector machines." ACM Transactions of Intelligent Systems and Technology (TIST) 2 (3): 1-39. doi:10.1145/1961189.1961199.

Collin, A., and J. L. Hench. 2012. "Towards deeper measurements of tropical reefscape structure using the WorldView-2 spaceborne sensor." Remote Sensing 4 (5): 1425-1447. doi:10.3390/rs4051425.

Collison, A., and N. Wilson 2017. "Planet Surface Reflectance Product." Accessed December 212017. https://assets.planet.com/marketing/PDF/Planet_Surface_Reflectance_Technical_White_Paper.pdf

Dekker, A., V. E. Brando, J. Anstee, S. Fyfe, T. Malthus, and E. Karpouzli. 2006. "Remote sensing of seagrass ecosystems: use of spaceborne and airborne sensors." In Seagrasses: Biology, Ecology and Conservation, edited by A. W. D. Larkum, R. J. Orth, and C. M. Duarte, 347-359. Dordrecht: Springer. doi:10.1007/978-14020-2983-7_15.

Dekker, A. G., S. R. Phinn, J. Anstee, P. Bissett, V. E. Brando, B. Casey, P. Fearns, et al. 2011. "Intercomparison of shallow water bathymetry, hydro-optics, and benthos mapping techniques in Australia and Caribbean coastal environments." Limnology and Oceanography Methods 9 :396-425. doi:10.4319/lom.2011.9.396.

Descartes Labs. 2017. "A data refinery, built to understand our planet." Accessed December 21 2017. https://medium.com/@DescartesLabs/announcing-our-30m-series-b-e658d58b4024 
Dierssen, H. M., R. C. Zimmerman, R. A. Leathers, T. V. Downes, and C. O. Davis. 2003. "Ocean color remote sensing of seagrass and bathymetry in the Bahamas Banks by high- resolution airborne imagery." Limnology and Oceanography 48: 444-455. doi:10.4319/lo.2003.48.1_part_2.0444.

Dörnhöfer, K., A. Göritz, P. Gege, B. Pflug, and N. Oppelt. 2016. "Water constituents and water depth retrieval from Sentinel-2A - A first evaluation in an oligotrophic lake." Remote Sensing 8 (11): 941. doi:10.3390/rs8110941.

Eugenio, F., J. Marcello, and J. Martin. 2015. "“'High-resolution maps of bathymetry and benthic habitats in shallow-water environments using multispectral remote sensing imagery." IEEE Transactions on Geoscience and Remote Sensing 53 (7): 3539-3549. doi:10.1109/TGRS.2014.2377300.

Fornes, A., G. Basterretxea, A. Orfila, A. Jordi, A. Alvarez, and J. Tintore. 2006. “Mapping Posidonia oceanica from IKONOS." ISPRS Journal of Photogrammetry and Remote Sensing 60 (5): 315-322. doi:10.1016/j.isprsjprs.2006.04.002.

Fourqurean, J. W., C. M. Duarte, H. Kennedy, N. Marba, M. Holmer, M. A. Mateo, E. T. Apostolaki, et al. 2012. "Seagrass ecosystems as a globally significant carbon stock." Nature Geoscience 5 :505-509. doi:10.1038/ngeo1477.

Fyfe, S. K. 2003. "Are seagrass species spectrally distinct?" Limnology and Oceanography 48: 464479. doi:10.4319/lo.2003.48.1_part_2.0464.

Gascon, F., C. Bouzinac, O. Thepaut, M. Jung, B. Francesconi, J. Louis, V. Lonjou, et al. 2017. "Copernicus Sentinel-2A calibration and products validation status." Remote Sensing 9 (6): 584. doi:10.3390/rs9060584.

Gernez, P., D. Doxaran, and L. Barillé. 2017. "Shellfish aquaculture from space: Potential of Sentinel2 to monitor tide-driven changes in turbidity, chlorophyll concentration and oyster physiological response at the scale of an oyster farm." Frontiers in Marine Science 4: 137. doi:10.3389/fmars.2017.00137.

Giannoulaki, M., A. Belluscio, F. Colloca, S. Fraschetti, M. Scardi, C. Smith, P. Panayotidis et al. 2013. Mediterranean Sensitive Habitats. DG MARE Specific Contract SI2.600741, Final Report. 557 pp.

Goodman, J. A., and S. L. Ustin. 2007. "Classification of benthic composition in a coral reef environment using spectral unmixing." Journal of Applied Remote Sensing 1. doi:10.1117/1.2815907.

Gordon, H. R., O. B. Brown, and M. M. Jacobs. 1975. "Computed relationships between the inherent and apparent optical properties of a flat homogeneous ocean." Applied Optics 14 (2): 417-427. doi:10.1364/AO.14.000417.

Harmel, T., M. Chami, T. Tormos, N. Reynaud, and P. A. Danis. 2018. "Sunglint correction of the Multi-Spectral Instrument (MSI)-SENTINEL-2 imagery over inland and sea waters from SWIR bands." Remote Sensing of Environment 204: 308-321. doi:10.1016/j.rse.2017.10.022.

Hedley, J., C. Roelfsema, and S. R. Phinn. 2009. "Efficient radiative transfer model inversion for remote sensing applications." Remote Sensing Environment 113: 2527-2532. doi:10.1016/j.rse.2009.07.008.

Jordà, G., N. Marbà, and C. M. Duarte. 2012. "Mediterranean seagrass vulnerable to regional climate warming." Nature Climate Change 2: 821-824. doi:10.1038/nclimate1533.

Klonowski, W., P. R. C. S. Fearns, and M. Lynch. 2007. "Retrieving key benthic cover types and bathymetry from hyperspectral imagery." Journal of Applied Remote Sensing 1 (1): 011505. doi:10.1117/1.2816113.

Landsat, 2017. U.S. Landsat Analysis Ready Data (ARD). Accessed December 21 2017. https:// landsat.usgs.gov/ard

Lee, Z., B. Casey, R. Arnone, A. Weidemann, R. Parsons, M. J. Montes, B. Gao, et al. 2007. "Water and bottom properties of a coastal environment derived from Hyperion data measured from the EO1 spacecraft platform." Journal of Applied Remote Sensing 1 :011502. doi:10.1117/1.2822610.

Lee, Z., K. L. Carder, C. D. Mobley, R. G. Steward, and J. S. Patch. 1998. "Hyperspectral remote sensing for shallow waters. I. A semianalytical model." Applied Optics 37 (27): 6329-6338. doi:10.1364/AO.37.006329.

Lee, Z., K. L. Carder, C. D. Mobley, R. G. Steward, and J. S. Patch. 1999. "Hyperspectral remote sensing for shallow waters: 2 . Deriving bottom depths and water properties by optimization." Applied Optics 38 (18): 3831-3843. doi:10.1364/AO.38.003831. 
Lee, Z., K. L. Carder, R. F. Chen, and T. G. Peacock. 2001. "Properties of the water column and bottom derived from Airborne Visible Infrared Imaging Spectrometer (AVIRIS) data." Journal of Geophysical Research 106: 11639-11651. doi:10.1029/2000JC000554.

Leriche, A., V. Pasqualini, C. F. Boudouresque, G. Bernard, P. Bonhomme, P. Clabaut, and J. Denis. 2006. "Spatial, temporal and structural variations of a Posidonia oceanica seagrass meadows facing human activities." Aquatic Botany 84: 287-293. doi:10.1016/j.aquabot.2005.10.001.

Lyzenga, D. R. 1978. "Passive remote sensing techniques for mapping water depth and bottom features." Applied Optics 17: 379-383. doi:10.1364/AO.17.000379.

Lyzenga, D. R. 1981. "Remote sensing of bottom reflectance and water attenuation parameters in shallow water using aircraft and Landsat data." International Journal of Remote Sensing 2 (1): $71-$ 82. doi:10.1080/01431168108948342.

Marbà, N., E. Díaz-Almela, and C. M. Duarte. 2014. "Mediterranean seagrass (Posidonia oceanica) loss between 1842 and 2009." Biological Conservation 176: 183-190. doi:10.1016/j.biocon.2014.05.024.

Mateo, M. A., and J. Romero. 1997. "Detritus dynamics in the seagrass Posidonia oceanica: elements for an ecosystem carbon and nutrients budget." Marine Ecology Progress Series 151: 43-53. doi:10.3354/meps151043.

Matta, E., M. Aiello, M. Bresciani, M. Gianinetto, M. Musanti, and C. Giardino. 2014. "Mapping Posidonia meadow from high spatial resolution images in the Gulf of Oristano (Italy)". Paper presented at the Geoscience and Remote Sensing Sympositum (IGARSS), IEEE International, Quebec City, Canada, July 13-18. doi: 10.1109/IGARSS.2014.6947658

Mishra, D. R., S. Narumalani, D. Rundquist, and M. Lawson. 2005. "High-resolution ocean color remote sensing of benthic habitats: a case study at the Roatan island, Honduras." IEEE Transactions on Geoscience and Remote Sensing 43: 1592-1604. doi:10.1109/TGRS.2005.847790.

Mobley, C. D. 1994. Light and Water: Radiative transfer in natural waters. Cambridge, MA: Academic Press.

Mobley, C. D., L. K. Sundman, C. O. Davis, J. H. Bowles, T. V. Downes, R. A. Leathers, M. J. Montes, et al. 2005. "Interpreation of hyperspectral remote-sensing imagery by spectrum matching and look-up tables." Applied Optics 44 (17): 3576-3592. doi:10.1364/AO.44.003576.

Morel, A. 1974. "Optical Properties of Pure Water and Pure Seawater." In Optical Aspects of Oceanography, edited by N. G. Jerlov and N. E. Steemann, 1-24. New York, NY, USA: Academic Press.

Morel, A., and B. Gentili. 1993. "Diffuse reflectance of oceanic waters: II: Bidirectional aspects." Applied Optics 32 (33): 6864-6879. doi:10.1364/AO.32.006864.

Mountrakis, G., J. Im, and C. Ogole. 2011. "Support vector machines in remote sensing: a review." ISPRS Journal of Photogrammetry and Remote Sensing 66: 247-259. doi:10.1016/j.isprsjprs.2010.11.001.

Nordlund, L. M., E. W. Koch, E. B. Barbier, and J. C. Creed. 2016. "Seagrass ecosystem services and their variability across genera and geographical regions." PLoS One 11: 1-23. doi:10.1371/ journal.pone.0163091.

Nordlund, L. M., R. K. F. Unsworth, M. Gullström, and L. C. Cullen-Unsworth. 2017. "Global significance of seagrass fishery activity." Fish and Fisheries 19 (3): 399-412. doi:10.1111/faf.12259.

Pacheco, A., J. Horta, C. Loureiro, and O. Ferreira. 2015. "Retrieval of nearshore bathymetry from Landsat 8 images: A tool for coastal monitoring in shallow waters." Remote Sensing of Environment 159: 102-116. doi:10.1016/j.rse.2014.12.004.

Pahlevan, N., S. Sarkar, B. A. Franz, S. V. Blasubramarian, and J. He. 2017. "Sentinel-2 MultiSpectral Instrument (MSI) data processing for aquatic science applications: Demonstrations and validations." Remote Sensing of Environment 201: 47-56. doi:10.1016/j.rse.2017.08.033.

Pasqualini, V., C. Pergent-Martini, G. Pergent, M. Agreil, G. Skoufas, L. Sourbes, and A. Tsirika. 2005. "Use of SPOT 5 for mapping seagrasses: an application to Posidonia oceanica." Remote Sensing of Environment 94: 39-45. doi:10.1016/j.rse.2004.09.010.

Pergent, G., H. Bazairi, C. N. Bianchi, C. F. Boudouresque, M. C. Buia, P. Clabaut, M. Harmelin-Vivien, et al. 2012. Mediterranean Seagrass Meadows: Resilience and Contribution to Climate Change Mitigation, A Short Summary, 40. Gland, Switzerland and Málaga, Spain: IUCN.

Stumpf, R. P., K. Holderied, and M. Sinclair. 2003. "'Determination of water depth with highresolution satellite imagery over variable bottom types." Limnology and Oceanography 48: 547556. doi:10.4319/lo.2003.48.1_part_2.0547. 
Telesca, L., A. Belluscio, A. Criscoli, G. Ardizzone, E. T. Apostolaki, S. Fraschetti, M. Gristina, et al. 2015. "Seagrass meadows (Posidonia oceanica) distribution and trajectories of change." Scientific Reports $5: 1-14$. doi:10.1038/srep12505.

Thorhaug, A., A. D. Richardson, and G. P. Berlyn. 2005. "Spectral reflectance of the seagrasses: Thalassia testudinum, Halodule wrightii, Syringodium filiforme and five marine algae." International Journal of Remote Sensing 1161: 1487-1501. doi:10.1080/01431160600954662.

Tomas, F., X. Turon, and J. Romero. 2005. "Seasonal and small-scale spatial variability of herbivory pressure on the temperate seagrass Posidonia oceanica." Marine Ecology Progress Series 301: 95107. doi:10.3354/meps301095.

Toming, K., T. Kutser, R. Uiboupin, A. Arikas, K. Vahter, and B. Paavel. 2017. "Mapping water quality parameters with Sentinel-3 Ocean and Land Colour Instrument imagery in the Baltic Sea." Remote Sensing 9: 1070. doi:10.3390/rs9101070.

Topouzelis, K., C. Spondylidis, S. Papakonstantinou, and N. Soulakelis. 2016. "The use of Sentinel-2 imagery for seagrass mapping: Kalloni Gulf (Lesvos Island, Greece) case study)." Proceedings of the SPIE 9688: 7. id. 96881F. doi:10.1117/12.2242887.

Traganos, D., B. Aggarwal, D. Poursanidis, K. Topouzelis, N. Chrysoulakis, and P. Reinartz. 2018b. "Towards global-scale seagrass mapping and monitoring using Sentinel-2 on Google Earth Engine: The Case study of the Aegean and lonian Seas." Remote Sensing 10: 1227. doi:10.3390/rs10081227.

Traganos, D., D. Cerra, and P. Reinartz. 2017. "Cubesat-derived detection of seagrasses using Planet imagery following Unmixing-based Denoising: Is small the next big?" Poster presented at the ISPRS Hannover Workshop, Hannover, Germany. June 6-9, 2017. doi: 10.5194/isprs-archivesXLII-1-W1-283-2017

Traganos, D., D. Poursanidis, B. Aggarwal, N. Chrysoulakis, and P. Reinartz. 2018a. "Estimating Satellite-Derived Bathymetry (SDB) with the Google Earth Engine and Sentinel-2." Remote Sensing 10: 859. doi:10.3390/rs10060859.

Traganos, D., and P. Reinartz. 2017. "Mapping Mediterranean seagrasses with Sentinel-2 imagery." Marine Pollution Bulletin. doi:10.1016/j.marpolbul.2017.06.075.

Traganos, D., and P. Reinartz. 2018. "Interannual change detection of Mediterranean seagrasses using RapidEye image time series." Frontiers in Plant Science 9: 96. doi:10.3389/fpls.2018.00096.

UN. 2017. "Goal 14: Conserve and sustainably use the oceans, seas and marine resources for sustainable development." Accessed December 20 2017. https://unstats.un.org/sdgs/report/2016/goal-14/

van der Linden, S., A. Rabe, M. Held, B. Jakimow, P. Leitão, A. Okujeni, and P. Hostert. 2015. "The EnMAP-Box - a toolbox and application programming interface for EnMAP data processing." Remote Sensing 7 (11): 11249-11266. doi:10.3390/rs70911249.

Vapnik, V. 1995. The Nature of Statistical Learning Theory. 188. New York:Springer-Verlag. doi:10.1007/978-1-4757-2440-0.

Waycott, M., C. M. Duarte, T. J. B. Carruthers, R. J. Orth, W. C. Dennison, S. Olyarnik, A. Calladine, et al. 2009. "Accelerating loss of seagrasses across the globe threatens coastal ecosystems." Proceedings of the National Academy of Sciences of the USA 160 (30): 12377-12381. doi:10.1073/ pnas.0905620106.

$\mathrm{Xu}$, H. 2006. "Modification of normalised difference water index (NDWI) to enhance open water features in remotely sensed imagery." International Journal of Remote Sensing 27 (14): 30253033. doi:10.1080/01431160600589179. 